5.

Derecho constitucional 



\title{
EL INTERÉS PÚBLICO COMO CONVERGENCIA ENTRE LA LIBERTAD DE EXPRESIÓN, EL ACCESO A LA INFORMACIÓN Y EL DERECHO A LA VIDA PRIVADA
}

[The Public Interest as Convergence Between Freedom of Speech, Access to Information And The Right to Private Life]

\author{
Ignacio Covarrubias Cuevas* \\ Universidad del Desarrollo, Santiago, Chile
}

\begin{abstract}
RESUMEN
Este artículo confronta la extendida afirmación de que la concurrencia de un interés público, de mano de la libertad de información, justifica injerencias en el derecho a la vida privada. Se afirmará que el discernimiento entre uno y otro es desafiante, ya que, en ocasiones, el resguardo de la vida privada trae consigo la protección de bienes o aspectos del interés público tan importantes como aquellos asociados al ejercicio de la libertad de informar y el derecho de acceso
\end{abstract}

\begin{abstract}
This article deals with the widespread assertion that public interest and freedom of information justify the interference with the right to private life. It will assert that discerning between one and the other is challenging, since safekeeping private life sometimes entails the protection of assets or matters in the public interest as important as those related to the exercise of the freedom of information and the right to access the information. Based on this, some guide-
\end{abstract}

ReCiBido el 13 de enero y ACEPTADO el 12 de marzo de 2015

* Doctor en Derecho por la Universidad de los Andes, profesor derecho constitucional en la Facultad de Derecho de la Universidad del Desarrollo. Dirección electrónica: icovarrubias@udd.cl El trabajo es parte de los compromisos del Proyecto FONDECYT No 11121381: "La intimidad de los funcionarios públicos frente a la leyes de prensa y de acceso a la información pública”. Agradezco a Fairús Docmac su colaboración como ayudante de investigación. 
a la información. En dicho contexto, se entregarán lineamientos que puedan contribuir a una mayor determinación normativa del interés público en la información, a que se refiere el artículo 30 de la Ley de Prensa.

\section{Palabras clave}

Vida privada - Libertad de informar - Acceso a la información pública - Interés público. lines will be provided to contribute to greater determination of the regulations on the public interest on information, as referred to by article 30 of the Chilean Press Act.

\section{KEYWORDS}

Private life - Freedom of information - Access to public information Public interest.

\section{ObJETO, ALCANCE y PERSPECTIVA DEL TRABAJO}

Con anterioridad hemos evaluado críticamente aquella noción que afirma que los funcionarios públicos poseen una intimidad más reducida que la de una persona ordinaria ${ }^{1}$. Otro abordaje se ha hecho respecto de algunos casos en que la vida privada de funcionarios o figuras públicas ha confrontado a la libertad de expresión y el derecho de acceso a la información ${ }^{2}$. Hemos dicho que varios argumentos esgrimidos (intimidad reducida de los funcionarios, proporcionalidad, entre otros) palidecen frente al interés público $(=\mathrm{i}$. p.), el que ha mostrado ser crucial para adjudicar las tensiones entre tales derechos. Pretendemos abordar la relación entre el i. p. y los derechos de un modo distinto al aproximado habitualmente. Se plantea un desafío a la noción según la que, constatada que sea la concurrencia de un i. p. en informar o en acceder a ésta, la prevalencia de aquél justifica su incursión en la vida privada ${ }^{3}$, como si el i. p. se encontrara sólo a un lado de la ecuación y su presencia siempre legitimara la invasión en aquel derecho.

Para lo anterior, constataremos, en primer lugar, cuán amplia es la aceptación de la aludida premisa. Luego, e identificado el i. p. como un

${ }^{1}$ Covarrubias Cuevas, Ignacio, Evaluación critica de la noción de que los funcionarios públicos tienen una intimidad más reducida que la de una persona ordinaria, en Revista Chilena de Derecho, 41 (2014) 3 pp. 871-906; y en Covarrubias Cuevas, Ignacio, La vida privada de las figuras públicas (Santiago, Thomson-Reuters, 2013), p. 474 .

${ }^{2}$ Covarrubias Cuevas, Ignacio, La vida privada de los funcionarios públicos frente a dos derechos: el acceso a la información pública y la libertad de expresión. (Criterios empleados por la jurisprudencia chilena y comparada y su importancia relativa), aceptado en Ius et Praxis, 21 (2015) 1.

${ }^{3}$ Asumo esta noción en Covarrubias Cuevas, I., La vida privada de las figuras públicas, cit. (n. 1). 
bien prevalente a otros intereses de orden social, advertiremos la necesidad de contribuir a una mayor determinación normativa del i. p. en la información, pues mientras para unos su concurrencia produce el desplazamiento de la vida privada, para otros, este derecho no podría ser sacrificado frente a consideraciones de i. p. . En tercer lugar, exhibiremos algunos fallos donde el derecho a la vida privada puede ser considerado como parte integrante del mismo i. p. y no como un escollo para la realización de éste. Asumido que el i. p. puede estar presente en la libertad de expresión y el acceso a la información como en el derecho a la vida privada, mostraremos que la resolución de estas tensiones puede también abordarse a partir de nociones que comparten una idea de colaboración entre los derechos y el i. p.

En tal contexto, daremos algunos lineamientos que puedan contribuir a discernir el i. p. a que se refiere el artículo 30 de la Ley $\mathrm{N}^{\circ} 19.733$, entre otras normas que incorporan el i. p. como elemento definitorio de la relación entre la libertad de informar y la vida privada.

\section{EL INTERÉS PÚBLICO COMO JUSTIFICACIÓN PARA LA INTROMISIÓN EN EL DERECHO A LA VIDA PRIVADA}

La afirmación de que las injerencias que una persona puede padecer en su vida privada están justificadas si hay un i. p. en su develación, tiene sustento en el Convenio europeo de derechos humanos y en la Convención interamericana de derechos humanos, en textos constitucionales, legales y en la doctrina y jurisprudencia. Esto, con prescindencia del método empleado para adjudicar ${ }^{4}$.

\section{Convenio Europeo de derechos humanos y Convención interamericana} de derechos humanos.

El Convenio Europeo de derechos humanos dice que las invasiones en este derecho sólo están justificadas "en tanto en cuanto esta injerencia esté prevista por la ley y constituya una medida que, en una sociedad democrática, sea necesaria para la seguridad nacional, la seguridad pública, el bienestar económico del pais, la defensa del orden y la prevención de las infracciones penales, la protección de la salud o de la moral, o la protección de los derechos $y$ las libertades de los demás". La Convención interamericana de derechos

${ }^{4}$ Covarrubias Cuevas, Ignacio, La renuencia del derecho británico a la regla optimizadora en el test de proporcionalidad (y la constatación del mismo resultado en el TC chileno), en Ortiz, David (coordinador), Tendencias actuales del Estado constitucional contemporáneo (Lima, Ara Editores, 2013), V, pp. 470-501; y, en Covarrubias CueVAS, Ignacio, La vida privada de las figuras públicas, cit. (n. 1).

${ }^{5}$ Convenio europeo de derechos humanos, 4 de noviembre de 1950, artículo 8,2. 
humanos prescribe que "nadie puede ser objeto de injerencias arbitrarias o abusivas en su vida privada, en la de su familia, en su domicilio o en su correspondencia" ", con lo cual admite, a contrario sensu, que pueden haber legítimas incursiones en tal derecho a condición que sean justas.

Aunque la Convención interamericana de derechos humanos no indica causales específicas, su contexto lleva al mismo resultado que en el caso del Convenio europeo de derechos humanos: que el estándar es el i. p., al igual que "el derecho de los otros, la protección de la salud, el orden, la seguridad y la moral públicas" constituyen -en la Convención como en el Convenioexpresas limitaciones para la casi totalidad de los derechos que admiten restricciones por motivos de i. p. Así, la libertad de expresión del artículo 10 del Convenio dice que su ejercicio puede restringirse por causa de "seguridad nacional o pública, la prevención del desorden o del crimen, protección de la salud o moralidad, resguardo de la reputación o derechos de terceros, la prevención de revelar información recibida bajo reserva o la preservación de la autoridad e imparcialidad de la justicia". A exigencias similares están sujetos la vida privada y la casi totalidad de los derechos no reconocidos de modo absoluto en tales textos, dejando a salvo de análogas intervenciones únicamente a unos pocos derechos?.

Una muestra de la tendencia expuesta es la Declaración de principios sobre la libertad de expresión de la Comisión Interamericana, que dice que "las leyes de privacidad no deben inhibir ni restringir la investigación $y$ difusión de información de interés público", con lo que reconoce que el parámetro para determinar si la invasión en la vida privada es arbitraria, es la ausencia o concurrencia del i. p.

La mayoría de la jurisprudencia del Tribunal Europeo de Derechos Humanos, de la Corte Interamericana de Derechos Humanos e, incluso, de la Corte de Justicia de Luxemburgo, es coincidente en que el medio para dilucidar la legitimidad en la restricción a un derecho es el "test" de proporcionalidad. Para los efectos de este trabajo sólo basta consignar que una de las pocas afirmaciones que pueden sostenerse, como un rasgo comúnmente admitido de este método, independiente de sus diversas modalidades, es que uno de los requisitos exigidos para que la medida restrictiva del derecho sea legítima es que persiga y satisfaga una "necesidad

${ }^{6}$ Convención americana de derechos humanos, 22 de noviembre de 1960, artículo 11,2 .

${ }^{7}$ El derecho a la vida sólo admite injerencias como la admisibilidad de la pena de muerte en ciertos casos. El derecho a no ser torturado ni a padecer esclavitud están consagrados en términos absolutos.

${ }^{8}$ Declaración de principios sobre libertad de expresión, octubre de 2000, principio No 10. 
social imperiosa", lo cual, creemos, es un modo sustantivamente equivalente de afirmar que lo que debe promoverse es el i. p. o a un aspecto del mismo?.

Ciertos textos fundamentales prevén nociones amplias para sujetar la limitación de la generalidad de los derechos reconocidos. La Carta canadiense y la Declaración de derechos de Nueva Zelanda exigen que las injerencias sean justificadas en una "sociedad democrática" 10 , mientras la Carta sudafricana prescribe que una limitación a los derechos debe ser "razonable y justificable en una sociedad abierta y democrática basada en la dignidad humana, igualdad y libertad"11. La Ley fundamental de Bonn somete el ejercicio del derecho al libre desarrollo de la personalidad a que no infrinja los derechos de otros ni ofenda el "orden constitucional o moralidad pública"12.

\section{Doctrina y jurisprudencia.}

La idea que el i. p. es la base justificante de intromisiones en la vida privada encuentra amplio apoyo en la doctrina constitucional nacional ${ }^{13}$ y comparada ${ }^{14}$. Algo similar se ha señalado en el derecho penal ${ }^{15}$. Evans

${ }^{9}$ Así en Covarrubias Cuevas, I., La vida privada de las figuras públicas, cit. (n. 1).

${ }^{10}$ Capitulo canadiense de derechos y libertades, parte I del Acta Constitucional de 1982, artículo 1 y, en sentido similar, Declaración de derechos de la Constitución de Nueva Zelanda de 1990, artículo 5.

${ }^{11}$ Constitución de Sudáfrica, Ley No 108 de 1996, artículo 36 (1).

${ }^{12}$ Ley fundamental de Bonn de la República Federal Alemana, de mayo de 1949, artículo 2 (1).

${ }^{13}$ Meins Olivares, Eduardo, Derecho a la intimidad y a la honra en Chile, en Ius et Praxis, 6 (2000) 1, pp. 311-312; Nogueira Alcalá, Humberto, Pautas para superar las tensiones entre los derechos a la libertad de opinión e información y los derechos a la honra y la vida privada, en Revista de Derecho de la Universidad Austral de Chile, 17 (2004), pp. 155-156; VivanCo MarTíneZ, Ángela, Curso de derecho constitucional. Aspectos dogmáticos de la carta fundamental de 1980 (Santiago, Ediciones Universidad Católica de Chile, 2006), p. 348; Corral TAlCiani, Hernán, Sobre la responsabilidad civil de los periodistas y de los medios de comunicación social por atentados a la honra, intimidad e imagen, en Información Pública, 4 (Escuela de Periodismo de la Universidad Santo Tomás, 2006) 2, pp. 253-286.

${ }^{14}$ Eguiguren Praeli, Francisco, La libertad de expresión e información y el derecho a la intimidad personal. Su desarrollo actual y sus conflictos (Lima, Palestra, 2004); FLORES, Oscar, Libertad de prensa y derecho a la intimidad de los funcionarios públicos (Buenos Aires, La Ley, 2004), pp. 416-417; Phillipson, Gavin, The Right of Privacy in England and Strasbourg Compared, en Kenyon, Andrew - Richardson, Megan (editores), New Dimensions in Privacy Law: International and Comparative Perspectives (Cambridge, Cambridge University Press, 2006), pp. 227-22.; BAZÁN, Víctor, El derecho a la vida privada y el derecho a la libertad de información en la doctrina y jurisprudencia de la Corte Suprema de Justicia argentina, en Estudios Constitucionales, 6 (2008) 1, pp. 117-131, entre otros.

${ }^{15}$ Novoa Monreal, Eduardo, Derecho a la vida privada y libertad de información. 
señala que entre las escasas excepciones que admiten la intromisión en la privacidad personal están los casos en que ello se justifica en vista a la debida administración de justicial". Cea afirma que: "no es suficiente alegar una finalidad de protección de valores intimos [...] para esquivar el imperativo de informar sobre cuestiones de interés supraindividual [...] lesionar el bien común, o dejar en riesgo la seguridad del Estado o la seguridad nacional' ${ }^{17}$. Otros añaden que "no obstante que los hechos por su naturaleza formen parte de la vida privada o familiar, no se incurre en infracción al difundirlos si está envuelto en ello un interés público superior" ${ }^{18}$.

Nogueira ha dicho que "la relevancia pública de la información es la única causa de legitimación para afectar el derecho a la privacidad" y tal información "es aquella que se refiere a asuntos de relevancia pública, a hechos o acontecimientos que afectan a las instituciones y funciones públicas, como asimismo, hechos o acontecimientos que afectan al conjunto de los ciudadanos, además de las conductas constitutivas de delito, las restricciones autorizadas por ley o por los tribunales de justicia competentes" 19 . Entre otras variantes del i. p., el autor alude al "desempeño de la función pública" ${ }^{20}$, reconociendo el derecho a informarse sobre aspectos de la vida personal del funcionario en cuanto ésta incida directamente en el cumplimiento de sus deberes funcionarios. En una línea similar se han pronunciado otros autores, quienes han identificado el i. p., ya sea, con "el interés de la sociedad toda

Un conflicto de derechos (2a edición, México D.F, Siglo Veintiuno, 1981), pp. 205206; Grisolía, Francisco, Libertad de expresión y derecho a la honra (Santiago, LexisNexis, 2004), pp. 108-111; Matus Acuña, Jean Pierre y Hernández Basualto, Héctor, Materiales de discusión presentados a la Comisión Foro Penal, Parte especial. Versión refundida de unidades 1 a 9, con las observaciones recibidas y las conclusiones arribadas en las sesiones del Foro Penal, en Política Criminal, D3 (2006) 1, p. 134; Díaz Tolosa, Regina, Delitos que vulneran la intimidad de las personas: Análisis crítico del artículo 161-A del Código Penal chileno en Ius et Praxis, 13 (2007) 1, pp. 297-298, a modo ejemplar.

${ }^{16}$ Evans DE LA CuAdra, Enrique, Los derechos constitucionales (Santiago, Editorial Jurídica de Chile, 1986), p. 172, dice que no hay injerencia en la vida privada si "está en juego la comisión de otros delitos".

${ }^{17}$ Cea Egaña, José Luis, Derecho constitucional a la intimidad y a la honra, en Revista de Derecho de la Universidad Católica del Norte, 5 (1998), pp. 39-41.

${ }^{18}$ Verdugo, Mario - Pffefer, Emilio - Nogueira, Humberto, Derecho constitucional (2a edición, Santiago, Editorial Jurídica de Chile, 1999), pp. 250-253.

${ }^{19}$ Nogueira Alcalá, H., Pautas para superar las tensiones, cit. (n. 13), pp. 155156.

${ }^{20}$ Ibíd., p. 156. 
[...] estatal como el no estatal ${ }^{21}$, o con distintas manifestaciones del i. p. así considerados por el ordenamiento jurídico y la Constitución ${ }^{22}$.

Pareciera que la doctrina citada no sólo concibe el i. p. como un bien superior cuya promoción justifica injerencias en la vida privada. También da la idea de cuáles son algunos de los bienes que configuran el i. p. o algunas de sus manifestaciones. Identifican la "seguridad nacional", la "administración de justicia", el correcto "desempeño de la función pública" como algunos de aquellos bienes cuyo compromiso legitimaría incursiones en la vida privada o cuya preservación impediría que la lesión de este derecho pueda ser considerado como un pretexto para cuidar la promoción de tales bienes o fines comunes.

Hemos visto que expresiones similares reconocen los textos jurídicos al prescribir que hay ciertas finalidades comunes -seguridad pública, prevención del desorden o del crimen, protección de la salud o moralidad, el resguardo de derechos de terceros- (designadas judicialmente bajo la expresión "necesidad social imperiosa") cuya consecución autoriza imponer restricciones al ejercicio del derecho a la vida privada. Esto ha sido confirmado por aquellas instancias jurisdiccionales que han sostenido que el criterio que justifica la intervención regulativa en el ejercicio de los derechos en general y en la vida privada, en particular, es el i. p., entendido éste como una "necesidad social imperiosa", "como aquello que afecta el bien común" o como ciertos "asuntos por razón de su objeto resultan de interés colectivo o general ${ }^{23}$ conocer o difundir. Así se ha pronunciado el Tribunal Europeo $^{24}$, el Tribunal de las Comunidades Europeas (particularmente en

${ }^{21}$ Lovera Parmo, Domingo, El interés público como estándar. Libertad de expresión y vida privada, en GonZÁLEZ, Felipe (editor), Libertad de expresión en Chile (Santiago, Universidad Diego Portales, 2006), p. 69. En p. 70 aclara que se trata, sin embargo, de un interés público mutable

${ }^{22}$ Ríos Labbé, Sebastián, El derecho a la intimidad en Chile y las últimas modificaciones en su protección civil, en MARTINIC, María Dora (coordinadora), Nuevas tendencias del derecho (Santiago, LexisNexis, 2004), pp. 123 ss. y 281.

${ }^{23}$ Tribunal Constitucional de España, rol 192/1999, FJ 7; rol 148/2001, FJ 6; rol 54/2004, FJ 3; a modo ejemplar. Véanse: Covarrubias Cuevas, I., La vida privada de las figuras públicas, cit. (n. 1), pp. 134-154. Asimismo, GonZÁlez CifuENTES, Carolina, El derecho a la intimidad de los altos cargos (Tesis doctoral de la Universidad de Salamanca, [visible en: http://gredos.usal.es/jspui/bitstream/10366/115568/1/ DDPG_Gonzalez_Cifuentes_C._El_derecho.pdf, pp. 153-171.

${ }^{24}$ Con habitualidad desde Corte Europea de Derechos Humanos, "The Observer and The Guardian v United Kingdom", 14 EHRR 153 [71]; hasta "Case of Editions Plon v. France", párrafo 42; y "Case of MGN Limited v The United Kingdom”, párrafo 139. También, ECHR, "Refah Partisi (Welfare) Party v. Turkey”, 37 E.H.R.R. 1 [135] y ECHR, "ÖZDEP v. Turkey”, 31 EHRR 674 [44], ha dicho que el motivo de la restricción al derecho debe ser "convincente e imperioso". 
derechos económicos $)^{25}$ y la Corte Interamericana ${ }^{26}$.

La Corte Interamericana, siguiendo al Tribunal Europeo, ha concluido, al interpretar el artículo 10 de la Convención (libertad de expresión) "que [las medidas] 'necesarias', sin ser sinónimo de 'indispensables', implica la existencia de una 'necesidad social imperiosa' y que para que una restricción sea 'necesaria' no es suficiente demostrar que sea 'útil', 'razonable' u'oportuna' [...]". Este aserto "que es igualmente aplicable a la Convención americana, sugiere que la 'necesidad' y, por ende, la legalidad de las restricciones a la libertad de expresión fundadas sobre el artículo 13.2" (que justifica los límites a esta libertad en pos del respeto a los derechos de los demás y la protección de ciertos fines públicos ${ }^{27}$ ) "dependerá de que estén orientadas a satisfacer un interés público imperativo" 28 .

Así, en el contexto de la Convención interamericana de derechos humanos y del Convenio europeo de derechos humanos, el uso del "adjetivo 'necesario', en el significado del artículo 10 \$ 2 supone la existencia de una 'necesidad social imperiosa" "29, por lo que afirmar-como lo hizo en "Mitterrand" (2004) - que una medida judicial que restringió el derecho a la libertad de expresión era "necesaria" para satisfacer la finalidad legítima de proteger los derechos de terceros, es un modo sustantivamente equivalente de decir que había en este caso un i. p. en evitar temporalmente el daño que la publicación del libro habría irrogado a la familia y a la reputación del fallecido ${ }^{30}$ y que este interés superaba, en las particulares circunstancias, el i. p. en publicar el texto. Un fundamento similar tuvo el Tribunal Europeo en "MGN v. U.K." (2011)

${ }^{25}$ Corte Europea de Justicia, "Hauer v. Land Rheinland-Pfalz", párrafo 30; y "Germany v. Council”, párrafo 78, y la jurisprudencia allí citada.

${ }^{26}$ Corte Interamericana de Derechos Humanos, "Claude Reyes y otros", párrafo 91.También: "Palamara vs. Chile”, párrafo 85; "Ricardo Canese vs. Paraguay", párrafo 96; "Herrera Ulloa vs. Costa Rica”, párrafo 121-123; "Opinión Consultiva OC-5/85: La Colegiación Obligatoria de Periodistas”, párrafo 46.

${ }^{27}$ Convención americana de derechos humanos, 22 de noviembre de 1960, artículo 13,2 .

${ }^{28}$ Corte Interamericana de Derechos Humanos, "Fontevecchia v. Argentina", párrafo 53, nota al pie 46, p. 20, y la jurisprudencia allí citada.

${ }^{29}$ ECHR, "Editions Plon v. France”, párrafo 42; ECHR 2004, reitera una regla invariable en su jurisprudencia

${ }^{30}$ ECHR, "Editions Plon v. France”, párrafo 47 ECHR 2004.

${ }^{31}$ ECHR, "Case of MGN Limited v The United Kingdom, párrafo 139 y los casos allí citados. 


\section{Penal'. \\ 3. El artículo 30 de la "Ley de prensa" y el artículo 161-A del "Código}

Las disposiciones legales aludidas son ejemplos de normas jurídicas en que el i. p. es uno de los factores cruciales para discernir si las conductas o hechos sancionados por ellas están o no justificadas con su concurrencia. Aunque la aludida norma del Código Penal no es el objeto directo de nuestro trabajo, de todos modos es interesante exhibirla no sólo porque el bien jurídico protegido es el derecho a la intimidad sino como un caso necesitado de criterios que contribuyan a discernir la concurrencia y ponderación del i. p.

El artículo 30 de la Ley $\mathrm{N}^{\circ} 19.733$ prescribe que el acusado por injurias a través de un medio de comunicación podrá exonerarse de responsabilidad siempre que "probare la verdad de la imputación", que ésta aludiere a "hechos determinados" y, que "se produjere con motivo de defender un interés público real" o que "el afectado ejerciere funciones públicas y la imputación se refiriere a hechos propios de tal ejercicio" 32 . El inciso tercero expresa que para los efectos de lo preceptuado en esta disposición "se considerarán como hechos de interés público de una persona" seis circunstancias que enumera a modo ejemplar entre las cuales una alude a los hechos "referentes al desempeño de funciones públicas" ${ }^{3}$. El inciso final señala que "se considerarán como pertinentes a la esfera privada de las personas los hechos relativos a su vida sexual, conyugal, familiar o doméstica, salvo que ellos fueren constitutivos de delito".

Para el artículo 30 de la "Ley de Prensa", hay i. p. si los antecedentes informados por los medios, además de ser veraces y determinados, afectaren a una persona que "ejerciere funciones públicas y la imputación se refiriere a hechos propios de tal ejercicio" o "referentes al desempeño de funciones públicas", siempre que los hechos no sean aquellos "relativos a su vida sexual, conyugal, familiar o doméstica". A menos que tales circunstancias fueren constitutivas de delito, en cuyo caso operaría una contra excepción.

Aunque se advierte que los hechos referidos al desempeño de quienes ejercen funciones públicas pueden revestir i. p., no se percibe el criterio evaluativo que, según las circunstancias del caso, contribuiría a guiar el discernimiento judicial acerca de cuándo un antecedente resguardado ordinariamente por el derecho a la vida privada configura un i. p. de tal

${ }^{32}$ Ley $\mathrm{N}^{\circ}$ 19.733: Sobre libertades de opinión e información y ejercicio del periodis$m o$, publicada el 4 de junio de 2001 , artículo 30 incisos $1^{\circ}$ y $2^{\circ}$. La norma agrega: "En estos casos, si se probare la verdad de la imputación, el juez procederá a sobreseer definitivamente o absolver al querellado, según correspondiere".

${ }^{33}$ Ibíd., artículo 30 inciso $3^{\circ}$. También se consideran de interés público: "b) Los realizados en el ejercicio de una profesión u oficio y cuyo conocimiento tenga interés público real'. 
entidad que justifique levantar el velo que protege la reserva. Un par de ejemplos que advierten la necesidad de una evaluación normativa del i. p. lo muestran algunas decisiones judiciales y del Consejo para la Transparencia, sobre las que nos referiremos enseguida.

El artículo 161-A CPen. tipifica algunas conductas, que pueden calificarse genéricamente como intromisiones subrepticias en una conversación, documento o acto de carácter privado, en algún soporte material, utilizando para ello cualquier tipo de medio tecnológico, sancionándose a quienes, sin autorización del afectado, en recintos particulares o lugares que no sean de libre acceso al público, interfieran la vida privada de otros. El inciso segundo sanciona a los que difundan las conversaciones, los documentos o los hechos fijados subrepticiamente en algún soporte material, es decir, a los que difundan lo tipificado en el primer inciso, a una o más personas ${ }^{34}$.

Pues bien, el inciso cuarto de la citada disposición legal "contempla una causal de justificación que se aplica a todas las conductas sancionadas en el artículo". Tal "justificación se refiere a una autorización legal o judicial que hace inaplicable la sanción a quienes efectúen las acciones tipificadas en los incisos anteriores" y dado que "no hace alusión a los parámetros utilizados tras la autorización" se pregunta la autora "si el interés público comprometido sería uno de ellos". Concluye que "el interés, relevancia o trascendencia pública de la información justificaría sus vulneraciones”35.

\section{NECESIDAD DE CONTRIBUIR A UNA MAYOR DETERMINACIÓN NORMATIVA} RESPECTO DEL INTERÉS PÚBLICO EN LA INFORMACIÓN

Constatada la relevancia de este criterio para dilucidar si cabe o no autorizar develaciones no consentidas en informaciones resguardadas por la intimidad, coincidimos en que "persiste el problema de qué se entiende por interés público, pues siendo un concepto abstracto requiere ser llenado de contenido a fin de concretizarlo" ${ }^{\text {"3 }}$. Se ha visto su identificación como un bien prevalente a otros bienes o intereses, su asociación con el bien común o con aspectos de éste (la salud o seguridad pública, el correcto

${ }^{34}$ Díaz Tolosa, R., cit. (n. 15), pp. 295 y 297.

${ }^{35}$ Ibíd., p. 301 (por todas).

${ }^{36}$ Ibíd., p. 299; Lovera Parmo, D., cit. (n. 21), p. 68: "el debate interesante [...] en tribunales, es qué es el interés público". Eva Parada, María José, Fallo "Páez con Barahona": libertad de expresión e interés público, en Anuario de Derechos Humanos, 1 (2005), p. 150: "Un elemento ausente entre las consideraciones [...] es el interés público [...] que no es ponderada en el fallo". Implícitamente en Jara VillaLobos, Camilo, Derecho a la privacidad, libertad de expresión e interés público: el caso "Cordero con Lara y otros”, en Anuario de Derechos Humanos, 10 (2014), pp. 163-173. 
desempeño de la función pública, etc.). Varios tribunales han acuñado nociones semejantes al aludir al i. p. que legitima intromisiones en la vida privada en nombre de la libertad de informar. Un ejemplo es la noción formulada por la Corte Interamericana en "Herrera Ulloa vs. Costa Rica" (2007), donde sostuvo que se afecta el i. p. en aquellas situaciones en que un funcionario o servidor público, en virtud de su conducta o hechos "compromete a la sociedad en su conjunto, incide sobre la marcha del Estado, afecta intereses o derechos generales, o le acarrea consecuencias importantes para la comunidad ${ }^{37}$. Esto ha sido reiterado por la misma Corte ${ }^{38} \mathrm{y}$ otros tribunales han formulado nociones similares ${ }^{39}$.

Aunque estos reconocimientos sobre lo que el i. p. representa dan cierta luz sobre su significado, no dicen mucho a la hora de revelar qué es aquello que -normativamente- justifica el carácter "prevalente" o "supraindividual" del i. p., cuya concurrencia legitimaría injerencias en la vida privada. Pues bien, mientras unos dan a entender ${ }^{40} \mathrm{o}$ afirman derechamente ${ }^{41}$ que la existencia de un i. p. debería producir el efecto de desplazar o sacrificar al derecho a la vida privada, otros autores, por el contrario, afirman que el derecho a la vida privada no puede ni debe capitular frente a consideraciones de i. p.

Lovera dice que, verificado un i. p., "el juez deberá inclinar la balanza a favor de la libertad de expresión; si no lo hay, en cambio, deberá hacerlo a favor de la vida privada". Lo reitera al señalar que "mientras exista interés público en conocer esa información, el derecho a la vida privada debería ceder en frente de la libertad de expresión" ${ }^{\prime 2}$. En una línea similar, menos explícita, Grisolía asocia el i. p. con el objeto de la libertad de informar que se logra en tanto su ejercicio permita la prioridad de ciertos bienes o

${ }^{37}$ Corte Interamericana de Derechos Humanos, "Herrera Ulloa vs. Costa Rica", párrafo 23, p. 7 (concurrencia del juez Sergio García R.).

${ }^{38}$ Corte Interamericana de Derechos Humanos, "Ricardo Canese vs Paraguay", párrafo 98, pp. 63-64; “Tristán Donoso v. Panamá”, párrafo 121; y "Fontevecchia v. Argentina”, párrafo 59, p. 21.

${ }^{39}$ Tribunal Constitucional de España, rol 83/2002, FJ 5; que cita, asimismo, Tribunal Constitucional de España, rol 115/2000, FJ 9. Se refieren al i. p. informativo como aquellos "hechos o circunstancias susceptibles de afectar al conjunto de los ciudadanos", esto es, de "relevancia comunitaria".

${ }^{40}$ Verdugo, M. - Pffefer, E. - Nogueira, H., cit. (n. 18), pp. 250-253, piensan que "no obstante que los hechos por su naturaleza formen parte de la vida privada o familiar, no se incurre en infracción al difundirlos si está envuelto en ello un interés público superior”.

${ }^{41}$ Grisolía, F., cit. (n. 15), p. 108; Lovera Parmo, D., cit. (n. 21), pp. 67-73.

${ }^{42}$ Lovera Parmo, D., cit. (n. 21) p. 70 y 73. La misma idea reitera en p. 75. 
fines "de mayor valor" ${ }^{43}$ que aquellos propios de la vida privada (el autor agrega la honra). Para otros, en cambio, los derechos nacen ajustados o delimitados, "pero por algo externo -otros derechos fundamentales, el orden público, la moral pública, el bien común- se lo constriñe, se reduce su alcance" ${ }^{44}$. Para ellos "no cabe decir entonces que el derecho o libertad deban 'ceder' ante otros bienes constitucionalmente protegidos" 45 .

Algunos parecen admitir que en cierto casos no habría conflicto entre preservar el i. p. y resguardar la vida privada (estaría la idea de que no hay legítimo derecho contra el bien común o alguno de sus expresiones, por ejemplo, la investigación y sanción de actos delictivos) ${ }^{46} \mathrm{y}$ otros someten el ejercicio del derecho a criterios prudenciales que podrían inclinar la balanza en uno u otro sentido ${ }^{47}$. Veremos que las diferencias antagónicas expuestas también se observan en ciertos fallos que han asignado distintos roles al i. p. en la modulación que le cabe entre la libertad de expresión, el derecho de acceso a la información y la vida privada. Excluiremos los casos en que el sacrificio de un derecho es consecuencia de una jerarquización previa, sea constitucional o judicialmente establecida, pues allí no hay, al menos formalmente, una ponderación casuística entre derechos que in abstracto son semejantes, sino que la decisión es más bien fruto de una valoración anticipada sentada por la justicia o prescrita por el mismo ordenamiento jurídico.

1. Extendida idea de que el interés público en la información desplaza la información resguardada por la vida privada.

Una muestra de la doctrina que acude a la noción de la prevalencia desequilibrante del i. p. frente a la vida privada lo exhiben algunos fallos del Tribunal Constitucional español. En su sentencia $N^{\circ}$ 171/1990, estableció que "para indagar si en un caso concreto el derecho de la informa-

${ }^{43}$ Grisolía, F., cit. (n. 15), p. 108.

${ }^{44}$ Serna Bermúdez, Pedro - Toller, Fernando, La interpretación constitucional de los derechos fundamentales. Una alternativa a los conflictos de derecho (Buenos Aires, La Ley, 2000), p. 20.

${ }^{45}$ De Otto y Pardo, Ignacio, Derechos fundamentales y constitución. (Madrid, Civitas, 1988), p. 143.

${ }^{46}$ Evans DE La CuAdra, E., cit. (n. 16), p. 172, dice que en casos en los que se investiguen delitos vinculados con la vida privada, entre otros similares: "No hay [...] intromisión [ilegítima] en la vida privada”.

${ }^{47}$ Cea Egaña, J. L., Derecho constitucional a la intimidad y a la honra, cit. (n. 17), pp. 39-41. Cea Egaña, José Luis, Vida pública, vida privada y derecho a la información: acerca del secreto y su reverso, en Revista de Derecho de la Universidad Austral de Chile, 3 (1992) 1-2, p. 22; y CeA EgaÑa, José Luis, Derecho constitucional chileno (Santiago, Universidad Católica de Chile, 2004), II, p. 382. 
ción debe prevalecer será preciso y necesario constatar, con carácter previo, la relevancia pública de la información" ${ }^{38}$. Esto fue reiterado y precisado más tarde al afirmarse que si la libertad de información "se ejerce sobre ámbitos que pueden afectar a otros bienes constitucionales, como [...] la intimidad, es preciso para que su proyección sea legitima que lo informado resulte de interés público" ${ }^{\prime \prime}$. Más adelante, el tribunal afinaría su noción de i. p., dando a entender que para que haya relevancia comunitaria "es decisivo determinar si nos encontramos ante unos hechos o circunstancias susceptibles de afectar al conjunto de los ciudadanos", reiterando la idea de que "la preservación de ese reducto de inmunidad sólo puede ceder, cuando del derecho a la información se trata, si lo difundido afecta, por su objeto y su valor, al ámbito de lo público"so.

No obstante que afirmaciones como las citadas han sido pronunciadas en casos en que se ha resguardado la intimidad, al estimar que lo develado no era en verdad de i. p., o que el i. p. en la información no justificaba revelar aspectos de la vida privada que no guardan "la más mínima conexión con el hecho de la información" ${ }^{51}$ de i. p., la falencia que se exhibe sigue inalterada, pues basta constatar que la información sea efectivamente de i. p. para que la vida privada tenga nulas o escasas posibilidades de resguardo, sin reparar que el i. p. -como interés o bien de la comunidad- también puede estar del lado de la intimidad.

En Chile, el Consejo para la Transparencia ha sido sincero sobre el punto al afirmar (junto al argumento de la reducida vida privada de los funcionarios) que "la privacidad debe ceder en pos del necesario control social

${ }^{48}$ Tribunal Constitucional de España, rol 171/1990, FJ 5. Aunque la oración añade que la relevancia de la información puede ocurrir "por el carácter público de la persona a la que se refiere o por el hecho en si en que esa persona se haya visto involucrada", hemos sostenido que el requisito del estatus de la persona involucrada ha mostrado ser accesorio respecto del "interés general que encierran los datos resguardados". Covarrubias Cuevas, I., La vida privada de las figuras públicas, cit. (n. 1), pp. 134-154; y GonZÁlez Cifuentes, C., cit. (n. 23), pp. 153-171.

${ }^{49}$ Tribunal Constitucional de España, rol 127/2003, FJ 8, agrega: "ello porque sólo entonces puede exigirse a quienes afecta o perturba el contenido de la información que, pese a tal circunstancia, la soporten, en aras, precisamente, del conocimiento general y difusión de hechos y situaciones que interesan a la comunidad. Es esa relevancia comunitaria -y no la simple satisfacción de la curiosidad ajena- lo unico que puede justificar la exigencia de que se asuman aquellas perturbaciones o molestias ocasionadas por la difusión de una determinada noticia, 'y reside en tal criterio, por consiguiente, el elemento final de valoración para dirimir, en estos supuestos, el eventual conflicto entre las pretensiones de información y de reserva". También los fallos allí citados, Tribunal Constitucional de España,, rol 121/2002, FJ 4; y rol 185/2002, FJ 4, entre otros.

${ }^{50}$ Tribunal Constitucional de España, rol 83/2002, FJ 5, en que se cita, también, Tribunal Constitucional de España, rol 115/2000, FJ 9.

${ }^{51}$ Tribunal Constitucional de España, rol 171/1990, FJ 4. 
que debe ejercerse" 52 en virtud del derecho de acceso a la información. Esto se entiende en un contexto en que para dicho organismo el derecho a la vida privada se opone a la "presencia de un bien jurídico superior, como es la publicidad y transparencia de los órganos del Estado a objeto de que la sociedad pueda ejercer un control social de la forma cómo se ejercen las funciones públicas" "33. En apoyo a este argumento, el Consejo para la Transparencia ha acudido también al artículo 30 de la "Ley de Prensa", que "califica como hechos de interés público los referentes al desempeño de funciones públicas" "54.

La lógica de lo expuesto es más o menos así: dado que la ley atribuye i. p. a los "hechos referentes al desempeño de funciones públicas", en la medida que la conducta o datos personales de alguien que ejerce una función pública permiten evaluar el desempeño, el conocimiento de estos antecedentes revestiría i. p., el cual al estimarse un bien jurídico superior, como la publicidad y transparencia, legitimaría el sacrificio de la vida privada frente a la prevalencia de un bien mayor. Una variante menos explícita de esto puede advertirse también en algunas disidencias de nuestro TC, donde se ha dicho que una vez enfrentadas la transparencia pública y el derecho a la vida privada, la proporcionalidad en sentido estricto ha de "identificar las ventajas que se obtendrían con la injerencia sobre el derecho al respeto de la vida privada [...] en relación con los beneficios que se producirían con el conocimiento público de la información requerida" 55 . Si bien no se afirma derechamente que la transparencia desplaza a la vida privada, al centrarse la adjudicación en las "ventajas" de invadir la vida privada con los "beneficios" asociados a la transparencia sin considerar las "ventajas o beneficios" que habría en resguardar la vida privada, se visualizaría un margen a favor de la transparencia en perjuicio de aquél.

\section{El reconocimiento de un interés público en la información transforma} lo privado en público y justifica su intrusión y difusión.

Algo similar dijo la Corte Suprema en "Doctora Cordero" (2013). Para denunciar la práctica de otorgar licencias médicas irregulares, dos

${ }^{52}$ Consejo para la Transparencia, Decisión A159-09, c. $19^{\circ}$. También: Decisión C707-12, c. $10^{\circ}$; Decisión C198-10, c. 20; Decisión A307-09, c. 15º Decisión A110-09, c. $8^{\circ}$ y 9o; Decisión A29-09, c. $8^{\circ}$.

${ }^{53}$ Corte de Apelaciones de Valparaíso, rol 1560-2012. Vistos de la sentencia, en que la Corte da cuenta de los argumentos utilizados en defensa del Consejo para la Transparencia.

${ }^{54}$ Consejo para la Transparencia, Decisión C95-10, c. $7^{\circ}$. También, Consejo para la Transparencia, A47-09, c. $12^{\circ}$.

${ }^{55}$ Tribunal Constitucional de Chile, rol 2.153-2011, c. $33^{\circ}$; disidencia de los ministros Francisco Fernández F., José Antonio Viera-Gallo Q. y Gonzalo García P. 
periodistas, simulando estar enfermos, concurrieron al despacho de la doctora para solicitarle el señalado permiso. Con cámaras ocultas grabaron la entrevista en que ella y otros profesionales otorgaban lo solicitado y luego difundieron las imágenes y el audio de la aludida conversación en un programa de televisión, sin que los afectados hubieran consentido en su grabación ni difusión. Se interpuso querella criminal en contra de los periodistas, el editor y el productor periodístico del programa que transmitió las imágenes. En primera instancia fueron condenados por infracción a los dos incisos del artículo 161-A C Pen. y al pago de una indemnización, todo lo cual fue confirmado por la Corte de Apelaciones.

El máximo tribunal, previa casación en el fondo, absolvió a los condenados de responsabilidad penal y civil. El argumento central fue que la conversación entre la doctora y los supuestos pacientes no habría sido privada debido al interés público en develar el otorgamiento irregular de una licencia médica, cuya difusión es un modo de prevenir la reiteración de este tipo de conductas. Así lo expresó: "El carácter privado desaparece cuando se trata de conductas que revisten un interés público. En el caso [...] si bien no se ha demostrado la comisión de un ilícito por los presuntos perjudicados, lo cierto es que su conducta importa al menos una transgresión a la ética por parte de profesionales de la salud que otorgaban licencias médicas falsas en desmedro de los demás cotizantes de los sistemas de salud, cuestión que reviste un interés público con mérito suficiente para ser socializada, lo que permitirá en último término, el fin de una situación reprobable e inconveniente" 56 . En apoyo a esto, y luego de reproducir parte del artículo 30 de la Ley $\mathrm{N}^{\circ} 19.733$, concluye que "los hechos que se atribuyen a los inculpados [...] acredita la legitimidad de su actuación inserta en el ejercicio de la función periodistica en aras de un interés social prevalente" 57.

Se asume la lógica de que la invasión a la intimidad se justifica en "aras de un interés social prevalente". La novedad aquí es que "el carácter privado desaparece cuando se trata de conductas que revisten un interés público", lo que se reitera en el mismo considerando al expresar el fallo que "no ha podido estimarse que la conversación de los periodistas con la profesional sea de carácter privado, pues se refiere a hechos que revelan irregularidades de la praxis médica verificables para ante la opinión pública" 58 .

No obstante admitimos la posibilidad de un desliz terminológico, lo

${ }^{56}$ Corte Suprema, rol 8393-2012, c. 5, reitera: "no ha podido estimarse que la conversación de los periodistas con la profesional sea de carácter privado, pues se refiere a hechos que revelan irregularidades de la praxis médica verificables para ante la opinión pública".

${ }^{57}$ Corte Suprema, rol 8.393-2012, c. $6^{\circ}$.

${ }^{58}$ Corte Suprema, rol 8.393-2012, c. $5^{\circ}$. 
que creemos que el fallo expresa es la idea de que el i. p. tendría la aptitud de mudar lo privado en público, esto es, que lo que es privado dejaría de serlo por estimarse que hay un interés público en los hechos o conductas resguardadas por la intimidad. Traduce la idea de que el interés público posee la aptitud de transformar, ontológicamente, lo privado en público. Así, con prescindencia de los matices expuestos, el resultado es similar a la idea expuesta de que basta identificar la concurrencia de un i. p. para que la vida privada pueda ser sacrificada en su nombre, sin afrontar un discernimiento acerca de si, según los hechos de la causa, podría haber existido un interés relevante en proteger la vida privada. Se desconoce así que el i. p. no sólo puede ser operativo como límite a la vida privada, como efectivamente lo reconoce este fallo ${ }^{59}$, sino también como legítima restricción a la libertad de expresión.

3. El resguardo del derecho a la vida privada impide la revelación de información de interés público.

La Corte de Santiago, al confirmar el fallo de primer grado del caso "Doctora Cordero" (2013), afirmó: "a pesar del notorio interés público que pudiera tener dicha noticia, no ha podido ser difundida por impedirlo la norma constitucional contemplada en el $N^{\circ} 4^{\circ}$ del artículo 19 de la Carta Fundamental, que asegura a todas las personas, lo siguiente: 'El respeto y protección a la vida privada y a la honra de las personas y su familia". Agregó que la citada garantía constitucional "encuentra su necesario respaldo en la norma penal antes señalada", y que ésta, el artículo 161-A CPen., "constituye un límite a la libertad de expresión, garantía establecida en el número 12 del referido artículo 19 de la Ley Fundamental' ${ }^{60}$, norma cuyo inciso $1^{\circ}$ transcribe.

De este modo, a pesar de reconocer la Corte el "notorio" i. p. que podría contener la información difundida, al confirmar el fallo, decide el asunto acudiendo al método de delimitación, por el cual basta constatar que las fronteras de un derecho fundamental han sido invadidas para que se le deba brindar protección a todo evento y frente a cualquier otra consideración ajena o externa a la misma consideración del derecho amagado.

Los casos expuestos demuestran que poco sirve estar de acuerdo en la relevancia más o menos determinante del i. p. en la tensión entre la libertad de expresión, el acceso a la información pública y el derecho a la vida privada, pues mientras algunos -autores y tribunales- piensan que la concurrencia del i. p. en un caso concreto produce o debe producir el efecto de

${ }^{59}$ Así es destacado en Jara Villalobos, C., cit. (n. 36), pp. 170-173.

${ }^{60}$ Corte de Apelaciones de Santiago, rol 1781-2011 ("Jaime Lara y otros con María Luisa Cordero"), considerando $3^{\circ}$. 
desplazar el derecho a la vida privada, otros, en las antípodas, estiman que no obstante haberse identificado un i. p. evidente en cierta información, su intrusión y posterior difusión está limitada por el resguardo al derecho a la vida privada. Esto muestra la necesidad de mostrar que existen casos en que el asunto es abordado desde una perspectiva que trascienda el todo o nada, donde el i. p. y la vida privada no sean necesariamente observadas como categorías excluyentes entre sí.

\section{LA DETERMINACIÓN NORMATIVA DEL INTERÉS PÚBLICO ESTÁ MODULADA POR NOCIONES CONTRAPUESTAS SOBRE EL BIEN COMÚN Y LOS DERECHOS}

Hemos visto en la doctrina y jurisprudencia revisada que la relación entre libertad de expresión, derecho de acceso a la información y vida privada está en cierto grado influida por la idea sobre la relación que debe haber entre el i. p. y los derechos. Afirmaremos que más allá de las dos posiciones más contrastantes, hay fallos que exhiben que los derechos -incluido la vida privada- pueden ser considerados como parte integrante del mismo i. p. y no necesariamente un escollo para su realización. Los criterios proponen que la valoración del i. p. como justificación de injerencias en la vida privada supone un proceso de discernimiento más desafiante del que ordinariamente se observa desde las posiciones más extendidas. Por ello efectuaremos una síntesis doctrinaria que pretende mostrar que las diferencias entre las posiciones más visiblemente contrapuestas entre sí remiten, en último término, a una idea en que los derechos aparecen confrontados al bien común.

\section{La posición extendida: disyuntiva entre promover el interés público y} resguardar los derechos.

Hay dos posiciones contrapuestas bastante difundidas sobre la relación entre el i. p. y los derechos. Una afirma que la pregunta a abordar en estos casos es cómo los tribunales deben optar entre proteger los derechos o resguardar el i. p., como si se tratase de opciones excluyentes entre sí. Para éstos, partidarios de una de las modalidades de la "ponderación del balanceo" ${ }^{61}$, lo central estriba en determinar si los beneficios de la medida restrictiva de un derecho superan los costos de su interferencia, lo que supone a su vez dilucidar cuál de los intereses en disputa posee mayor

${ }^{61}$ No todos los partidarios del test asumen su versión "optimizadora", como afirmamos en Covarrubias Cuevas, I., La renuencia, cit. (n. 4); y Covarrubias Cuevas, Ignacio; ¿Emplea el Tribunal Constitucional el test de proporcionalidad? en Estudios Constitucionales, 12 (2014) 1, pp. 163-237. 
"peso" conforme a los hechos del caso. Uno de sus representantes más insignes es Alexy ${ }^{62}$, entre otros autores ${ }^{63}$.

La noción opuesta busca fortalecer los derechos frente a la amenaza representada por el i. p. . Se propone una alternativa deontológica al aludido método de balanceo, que estiman consecuencialista. Afirman que los derechos son sustancialmente prioritarios respecto de los intereses colectivos. Mientras Dworkin afirma que los derechos son "triunfos" frente a los intereses colectivos en cuanto no pueden quedar sujetos a un cálculo utilitario de costo-beneficio ${ }^{64}$, Habermas dice que los derechos poseen una "mayor fuerza justificadora" que los "valores" 55 . Según la precedencia que los derechos tendrían sobre las consideraciones colectivas o generales, señala que hay "un cortafuego" que encapsula a los derechos de la injerencia regulativa por motivos de política pública ${ }^{66}$.

Una tercera derivada, comunitarista, postula que los derechos no pueden permanecer intocados frente al bien común. La idea es superar una concepción atomista del individuo y de la sociedad que ve los derechos como medios de la autonomía frente al Estado y la sociedad ${ }^{67}$. Admite tantas variaciones que no me atrevería a hacerla extensiva a todos los exponentes del comunitarismo más allá de lo aquí dicho ${ }^{68}$. Lo que parece claro es que la crítica tiene asidero en un contexto que asume que los derechos son estimados prerrogativas híper-individualistas ${ }^{69}$. Un comunitarista ha

${ }^{62}$ Alexy, Robert, $A$ Theory of Constitutional Rights (New York, Oxford University, 2002), p. 50; y Alexy, Robert, On Balancing and Subsumption. A Structural Comparison, en Ratio Juris, 16 (2003) 4.

${ }^{63}$ Fallon, Richard, Individual Rights and the Powers of Government, en Georgia Law Review, 27 (1993), pp. 343-390; Bernal Pulido, Carlos, El principio de proporcionalidad y los derechos fundamentales (Madrid, Centro de Estudios Políticos y Constitucionales, 2003), p. 871; Kumm, Mattias, Constitutional Rights as Principles: On the Structure and Domain of Constitutional Justice, en International Journal of Constitutional Law, 2 (2004), pp. 574-596.

${ }^{64}$ Dworkin, Ronald, Taking Rights Seriously (Cambridge, Harvard University Press, 1977), p. 191. En pp. 92 y 191, el autor admite que hay casos en que los derechos no deben prevalecer sobre los intereses colectivos, pero ello se entiende en cuanto su sacrificio sea para asegurar los más altos objetivos sociales.

${ }^{65}$ Habermas, Jürgen, Between Facts and Norms: Contributions to a Discourse Theory of Law and Democracy (Cambridge, MIT - U. Press, 1996), p. 259.

${ }^{66}$ Habermas, J., cit. (n. 65), pp. 258-259.

${ }^{67}$ Prado, Maximiliano, Limitación de los derechos humanos. Algunas consideraciones teóricas, en Revista Chilena de Derecho, 34 (2007) 1, p. 62.

${ }^{68}$ MacInTyre, Alasdair, Tras la virtud (Madrid, Austral, 2013), pp. 95-96, afirma que los derechos no son más que ficciones modernas que socavan el bien común.

${ }^{69}$ Glendon, Mary Ann, El lenguaje de los derechos, en Estudios Públicos, 70 (1998), pp. 70-150. 
dicho que "la privacidad no tiene un valor absoluto ni tampoco triunfa frente a todos los otros derechos o intereses cobijados por el bien común" ${ }^{\prime \prime 0}$. Esto ocurre porque este derecho es visto como "una licencia para actuar" que deja una serie de conductas inmunizadas frente al i. p. La labor de los jueces consistiría por tanto, en "equilibrar los derechos individuales con las responsabilidades sociales, esto es, el individuo con su comunidad"71.

Para los partidarios del balanceo optimizador ${ }^{72}$, no hay razón para resguardar un derecho si las consecuencias de hacerlo son, en el cálculo entre costos y beneficios, perjudiciales para el i. p. Así lo reconoce Alexy al señalar que "la convicción de que debe haber derechos que aún en las más extremas circunstancias no sean sobrepasados [...] no puede ser sostenido en el derecho constitucional"73. En cambio, para Dworkin y Habermas, entre otros ${ }^{74}$, los derechos en general deben ser protegidos "aun cuando las consecuencias sean, comparativamente, perjudiciales"75. En esta línea, Schauer, se refiere al i. p. y a los derechos como "inconmensurables" entre sí, en el sentido que el mal que supone la violación de los derechos no puede ser medible en los mismos términos con los beneficios sociales que su infracción traería aparejados ${ }^{76}$.

No obstante las posiciones expuestas se aproximan al i. p. y a los derechos como "valores contrapuestos" ("competing values") entre si ${ }^{77}$, hay algo que ambas posiciones asumen ab initio más allá de sus diferencias antagónicas: comparten que los intereses sociales o generales colisionan con

${ }^{70}$ Etzioni, Amitai, The Limits of Privacy (Nueva York, Basic Book, 1999), pp. 187-188.

${ }^{71}$ Ibíd., pp. 196 y 198.

${ }^{72}$ En Covarrubias Cuevas, I., Emplea, cit. (n. 61), pp. 167 ss., hemos exhibido en qué consiste.

${ }^{73}$ Alexy, R., $A$ Theory, cit. (n. 62), p. 196. Con todo, para el autor hay casos -la esclavitud, la tortura o la discriminación racial- que no serían justificables]: ALEXY, Robert, Teoría de la argumentación jurídica: La teoría del discurso racional como teoría de la fundamentación jurídica (traducción de M. Atienza e I. Espejo, Madrid, Centro de Estudios Constitucionales, 1989), pp. 137-138; y AlEXY, Robert, El concepto y la validez del derecho (traducción de J. M. Seña, Barcelona, Gedisa, 1997), pp. 54 y 67.

${ }^{74}$ Schauer, Frederick, A Comment on the Structure of Rights, en Georgia Law Review, 27 (1993), p. 429.

${ }^{75}$ Meyerson, Denise, Why Courts Should Not Balance Rights against The Public Interest, en Melbourne University Law Review, 31 (2007), p. 886.

${ }^{76}$ SCHAUER, Frederick, Commensurability and Its Constitutional Consequences, en Hastings Law Journal, 45 (1994), p. 790.

${ }^{77}$ Aleinikoff, Alexander, Constitutional Law in the Age of Balancing, en Yale Law Journal, 96 (1987), pp. 943 y 945; Gardbaum, Stephen, Limiting Constitutional Rights, en UCLA Law Review, 54 (2007), pp. 789-854; Meyerson, D., cit. (n. 75), a modo ilustrativo. 
los derechos individuales, por lo que la solución no puede ir de la mano de ponderar o ajustar unas y otras pretensiones sino en hacer prevalecer incontestadamente unas por sobre las otras. Esto se explica en el contexto iniciado por la modernidad según la cual el poder (la ley) y la sociedad son estimadas amenazas a la libertad (derechos) al punto que la disyuntiva habitualmente concebida haya sido optar entre uno y otro, "como si la comunidad sofocara la libertad individual, o la libertad no casara bien con la idea de bien común"78. El discurso liberal clásico concibió a los derechos como la moneda de cambio para obtener estabilidad y seguridad.

En la jurisprudencia que se exhibirá, observaremos, en cambio, la idea de continuidad entre derechos e i. p., de modo que la disyuntiva de optar entre aquél y éstos no es siempre identificada como la mejor ni la única opción, por lo que el discernimiento ha de traducirse en una ponderación entre el ejercicio legítimo de un derecho y la satisfacción del i. p., ambos considerados como distintos aspectos de un interés común, a fin determinar de qué lado se encuentra el mayor bien en el caso concreto.

\section{LA CONTINUIDAD ENTRE LOS DERECHOS Y EL BIEN COMÚN:} AQUELLOS PUEDEN SER PARTE DEL INTERÉS PÚBLICO POR PRESERVAR POR LO QUE NO NECESARIAMENTE DEBE EXISTIR OPOSICIÓN ENTRE AMBOS

Hemos observado la función prevalente -y según algunos incontrarrestable- que puede desempeñar el i. p. cuando va de la mano de la libertad de informar o del derecho de acceso a la información pública. Advertiremos que de cara al i. p. en la transparencia, la información de interés comunitario y la "accountability", pueden identificarse otros intereses públicos análogos o de mayor relevancia que pueden aconsejar postergar el i. p. en la información para resguardar el i. p. en la reserva o en la vida privada. Esto puede tener lugar porque el resguardo asociado a dichos bienes -reserva o vida privada - trae consigo la preservación de un i. p. mayor que la difusión, o bien, porque el i. p. carece de la suficiencia necesaria para contraponerse a la vida privada. También puede considerarse que el aspecto de la vida privada en juego es tan sensible o sustantivo que se estima que no puede quedar sujeto a consideraciones ulteriores de orden colectivo. Aunque la mayoría de los casos la libertad de expresión y el acceso a la información confrontará el derecho a la vida privada de funcionarios o servidores públicos, de todos modos incluiremos algunos fallos referidos

${ }^{78}$ Poole, Diego, Bien común y derechos humanos, en Persona y Derecho, 59 (2008), p. 105. 
al i. p. en la vida privada de ciertas figuras públicas, atendido el interés de los criterios allí consignados.

1. El interés público en la reserva de información puede ser mayor que el interés público en su difusión.

El caso "Mitterrand" (2004), resuelto por el Tribunal Europeo, se refiere a la publicación de un libro, escrito por el médico del ex mandatario galo, en el que se revelaban antecedentes indudablemente protegidos por el derecho a la confidencialidad, tal como lo manifestaron las distintas instancias judiciales francesas y así lo reconoció el Tribunal ${ }^{79}$. El libro devela que al presidente francés se le había diagnosticado un cáncer a los pocos meses de ser electo por primera vez y que dicha enfermedad había sido ocultada al público desde entonces. Enterada la familia de la existencia del libro, solicitó a la justicia una medida cautelar para impedir su difusión. La medida judicial fue expedida con carácter temporal.

Aunque el tribunal reconoció que la publicación versaba sobre un asunto de indudable i. p., a saber, "ser informado sobre cualquier enfermedad grave padecida por un jefe de Estado, y el tema acerca de si una persona que sabía que estaba seriamente enferma era apta para asumir la más alta magistratura de la nación" ${ }^{80}$, se estimó de todos modos que la expedición de una orden judicial provisional que impedía transitoriamente la distribución era " $n e-$ cesaria en una sociedad democrática' para proteger los derechos del Presidente Mitterrand y sus familiares" ${ }^{\prime \prime}$. Superadas las circunstancias que motivaron el resguardo de los familiares del ex Presidente galo, el Tribunal Europeo estimó que la orden judicial preventiva, otorgada transitoriamente, había sido legítima pero no aquella que había sido expedida posteriormente con carácter indefinido.

Interesante es recordar que bajo la interpretación jurisprudencial del Tribunal Europeo, afirmar, en el contexto del artículo 10,2 de la Convención europea, que la restricción a la libertad de expresión era una medida "necesaria en una sociedad democrática" para proteger la vida privada de terceros, es lo mismo que decir -como ya se explicitó- que existía "una "necesidad social imperiosa" ${ }^{82}$, esto es, un i. p. de relevancia, en la reserva de la información resguardada por la intimidad, a fin de evitar el daño que la publicación del texto habría irrogado a los familiares del ex mandatario y a la reputación del fallecido ${ }^{83}$.

\footnotetext{
${ }^{79}$ ECHR, "Editions Plon v. France", párrafos 18-19, ECHR 2004.

${ }^{80}$ Ibíd., párrafo 44, ECHR 2004.

${ }^{81}$ Ibíd., párrafo 48, ECHR 2004.

${ }^{82}$ Ibíd., párrafo 42, ECHR 2004, reitera una regla invariable en la jurisprudencia.

${ }^{83}$ Ibíd., párrafo 47, ECHR 2004.
} 
Así, no obstante que el i. p. en la reserva superó el inicio el i. p. contenido en la información del texto, el paso del tiempo ${ }^{84}$, entre otras circunstancias, convencieron al Tribunal Europeo de que la prohibición indefinida de publicarlo ya no era suficientemente justificada a la luz de los bienes en juego. Expresó que "mientras más tiempo pasaba, más prevalecía el interés público en la discusión de la historia de los dos periodos presidenciales del presidente Mitterrand por sobre las exigencias de proteger los derechos del Presidente a la confidencialidad médica".

Esto no significa que la Corte crea que la presencia de información de i. p. "pueda liberar a los profesionales médicos de su deber de resguardar la confidencialidad médica [...] salvo en casos estrictamente excepcionales establecidos por ley. Sin embargo, una vez que el deber de confidencialidad ha sido infringido, generando sanciones penales ( $y$ disciplinarias) contra el responsable, el paso del tiempo debe ser tomado en consideración para valorar si las serias medidas, tales como la prohibición de un libro-la cual en este caso fue general y absoluta-era compatible con la libertad de expresión”. Dado que “40.000 copias se habian vendido [entre la primera prohibición y la segunda] y el texto se encontraba diseminado en internet y habia sido objeto de comentarios de prensa [...] la información contenida habia dejado, en gran medida, de ser confidencial en la práctica. Por tanto, el resguardo de la confidencialidad ya no podía constituir una exigencia de la mayor prioridad"85.

Lo más relevante no parece ser que la reserva de información puede superar el interés en difundirla, sino que esto sucede porque, de cara al i. p. en la información de relevancia comunitaria, también hay un i. p. en el resguardo de la misma información. El Tribunal Europeo observa una "necesidad social imperiosa" no sólo en la protección de la libertad de expresión en un asunto de i. p. sino también en el resguardo de la vida privada de la confidencialidad médica. Más allá de los familiares del gobernante es posible identificar un i. p. en la reserva médica. Desconocer la confidencialidad en aras de un bien superior no sólo perjudica la intimidad de los directamente afectados sino que se lesiona la confianza que todos depositamos en la idea que nuestros antecedentes médicos, aún de los gobernantes, sean estimados asuntos habitualmente reservados. Así, del mismo modo en que hay un i. p. en preservar la reserva médico-paciente, también hay un i. p. en la necesidad de clarificar que los gobernantes no pueden esconder deliberadamente sus limitaciones físicas o mentales cuando estas pueden afectar el desempeño de su cargo público.

${ }^{84}$ Ibíd., párrafo 53, ECHR 2004, donde se constata que cuando la Corte superior francesa otorgó la prohibición "François Mitterrand llevaba muerto 9 meses y medio".

${ }^{85}$ Ibíd., párrafo 53, ECHR 2004 (por todas). 
Algo similar ocurrió en un caso resuelto por la Corte Suprema de Estados Unidos sobre el derecho de acceso a la información y a la vida privada. En "Depart. of State v. Ray" (1991), un abogado que representaba a ciudadanos haitianos que buscaban asilo político en norteamérica pidió acceder a los documentos que contenían información sobre aquellos haitianos que habían sido deportados a su país. Esto, con el objetivo de constatar si el organismo requerido estaba cumpliendo la política pública comprometida de supervigilar la protección de haitianos deportados para evitar su persecusión una vez que hubieren regresado. Al disponerse de información sobre la individualización de los deportados sería posible contactarlos para verificar el estado en que se encontraban ${ }^{86}$.

El ente requerido acogió parcialmente la solicitud con la salvedad de los nombres y de la situación social y familiar de los deportados, antecedentes que fueron denegados por estimarse una invasion "claramente injustificada" ${ }^{87}$ a la privacidad de los haitianos. Llegado al máximo tribunal, este sostuvo que aunque había un indudable i. p. en saber si el ente requerido había cumplido la política comprometida (de cuya eficacia dependía en la protección de haitianos deportados), el interés en proteger la privacidad y seguridad de éstos era superior ${ }^{88}$. La decisión unánime no sólo se fundó en que se revelaría información personal sino en que su develación "violaría la confianza que los haitianos han puesto en la confidencialidad de la información entregada al Departamento de Estado" y, además, "los expondría a la persecusión, maltrato y otras represalias" 89.

El fallo no se contenta en abordar el asunto bajo la lógica de contraponer i. p. versus vida privada ${ }^{90}$, ni se funda únicamente en la lesión a la privacidad y seguridad en cuanto bienes individuales de los directamente afectados, sino también en el perjuicio que de dicha infracción se seguiría para la confianza que los haitianos han puesto en el resguardo de su confidencialidad, es decir, en un aspecto del i. p. -la confianza- cuya preservación constituye un bien participable por todos. Así y aunque la información

${ }^{86}$ Halstuk, Martin, Blurred Vision: The Supreme Court's FOIA Opinions on invasion of privacy, en DAvis, Charles - Splichal, Sigman (editores), Access Denied. Freedom of Information in the Information Age (Iowa, Iowa State University Press, 2000), p. 136.

${ }^{87}$ Ley federal de acceso a la información pública de Estados Unidos, del 4 de julio de 1966, 5 U.S.C. $\$ 552$, (b) 6, que excepciona del derecho de acceso a los "documentos personales, médicos u otros similares cuya revelación pública constituiría una clara e injustificada invasión a la privacidad".

${ }^{88}$ Corte Suprema de los Estados Unidos, "U.S. Dept. of State v. Ray”, 502 U.S. 164.

${ }^{89}$ Ibíd., 173-179 (por todas).

${ }^{90}$ Halstuk, M., cit. (n. 86), p. 137. 
requerida era de i. p. y cuadraba dentro de los propósitos de la Ley de acceso a la información (según los criterios sentados por la Corte previamente ${ }^{91}$ ), el i. p. asociado al resguardo de la privacidad se estimó superior.

Otro caso de interés en Inglaterra es "Anderson vs. el Comisionado para la Información" (2011). Debe advertirse que no obstante la Ley de acceso a la información impide absolutamente acceder a los datos propios y de terceros ${ }^{92}$, el Comisionado de la Información inglés y el Tribunal de Información Pública han dicho que la revelación de datos de un tercero es excepcionalmente procedente ya que la misma Ley de acceso a la información formula la prohibición en términos condicionales: siempre que no se "contravenga (i) ninguno de los principios de [la Ley de] protección de datos, o (ii) la sección 10 de dicha Ley (el derecho a impedir que el procesamiento de datos pueda causar eventual perjuicio o aflicción" ${ }^{3}$. Como los principios de protección de datos personales no se encuentran redactados como "una lista prescriptiva de lo que se puede y no se puede", se ha interpretado que antes que impedir la transparencia, lo que hay que buscar es el acomodo o equilibrio entre el acceso a la información pública y la protección de la vida privada ${ }^{94}$.

Interesante es que una de las condiciones que la Ley de acceso a la información inglesa exige para que "los datos personales sean procesados justa y legalmente" 95 están los motivos de interés público, esto es, "que [la entrega] sea necesaria (a) para la administración de justicia, (aa) para el ejercicio de las funciones de cualquiera de las Cámaras del Parlamento [...], (c) para el ejercicio de las funciones de la Corona, de un Ministro de la Corona o de un departamento gubernamental, o (d) para el ejercicio de cualquier otra función de naturaleza pública desempeñadas en el interés público por cualquier persona" ${ }^{\text {". }}$. Las condiciones para procesar los datos sensibles son similares con la salvedad que aquí se excluye la posibilidad de revelar los datos en beneficio de una función de interés público.

En dicho contexto, en "Anderson vs. el Comisionado para la Información” (2011), éste, el Tribunal de Información Pública y la Corte Superior

${ }^{91}$ Corte Suprema de Estados Unidos, "Dept. of Justice v. Reporters Committee for Freedom of the Press", 489 U.S. 775: el propósito central de la Ley federal de acceso a la información pública es "contribuir significativamente a la pública comprensión de las operaciones o actividades del gobierno".

${ }^{92}$ Freedom of Information Act, 2000, chapter 36, de 2000, Section 40.

${ }^{93}$ Ibíd., chapter 36, de 2000, Section 40 (3) (a) (i) y (ii).

${ }^{94}$ Turle, Marcus, Freedom of Information and Data Protection Law. A Conflict or Reconciliation? en Computer Law \& Security Report, 23 (2007) 6, p. 517.

${ }^{95}$ Data Protection Act, 1998, chapter 29, de 1998, Section 1 (a) y (b).

${ }^{96}$ Ibíd., chapter 29, de 1998, Schedule 2, (5) (a), (aa), (c) y (d), (la cursiva es nuestra). 
estuvieron por denegar la solicitud de conocer los detalles de los reclamos que terceros habían efectuado en contra de la conducta de personas que habían participado en una marcha autorizada. Si bien el requerimiento del organizador de la parada excluía el nombre de las personas que habían hecho las denuncias, el Comisionado denegó la entrega de la información. Aunque reconoció que "hay un poderosos interés público en conocer sobre las polémicas conductas ocurridas en marchas en el Norte de Irlanda”, estimó que "atendida la naturaleza de la información, había una expectativa de parte de los denunciantes en que la información debía ser mantenida en reserva, pues también el Comisionado "está consciente del interés público en asegurar que la gente no sea desincentivada a expresar sus opiniones sobre la actuación de las autoridades por la vía de publicar la información que han proveido"'

El comisionado afirmó que si bien la ley prevé una excepción absoluta no sujeta al test de interés público, debe admitirse "que en ciertas circunstancias el interés público puede superar el deber de reserva. Cuando hay un prevalente interés público en revelar la información, los tribunales han aceptado que ningún deber de reserva es debido"98. El Tribunal de Información Pública desechó la apelación frente a la negativa del Comisionado y sostuvo que si bien la Ley de acceso a la información establece una excepción absoluta al acceso, "sólo en la medida que el interés público esté comprometido en un caso concreto, el interés en revelar puede ser tan poderoso como para que el deber de reserva deba ser dejado de lado" ${ }^{\prime 9}$. En fin, todas las instancias concluyeron que no obstante el i. p. en conocer las causas de ciertos desórdenes en marchas públicas, "el interés público en proteger la reserva de los que proveen información en estas circunstancias es [...] muy poderoso" por lo que "el interés público derechamente favorece el rechazo de la información" 100 requerida por el recurrente.

Interesante es observar la presencia del i. p. en bienes jurídicos habitualmente asociados a la protección de derechos vistos como contrapuestos al mismo i. p. De ahí la necesidad de descartar que éste sólo posea un sitial preponderante para los efectos de discernir la legitimidad en develar información protegida por la intimidad sino también en el resguardo de

${ }^{97}$ Corte Suprema de Justicia de Irlanda del Norte (Queen's Bench Division Decisions), "Keith Anderson v. The Information Commissioner", párrafo 7 que cita los párrafos 27, 29 y 30 de la resolución del Comisionado.

${ }^{98}$ Ibíd., párrafo 7 que cita el párrafo 28 de la resolución del Comisionado.

${ }^{99}$ Ibíd., párrafo 11 que cita el párrafo 31 de la resolución del Tribunal de la Información, en que cita, a su vez, Corte de Justicia, Derry Irlanda del Norte, "Derry City Council v. Information Commissioner”, párrafo 35 (m).

${ }^{100}$ Ibíd., párrafo 11 que cita los párrafos 33 y 34 de la resolución del Tribunal de la Información. 
ésta. Hay otros ejemplos en que también se ha reconocido implícitamente i. p. en la reserva ${ }^{101}$, pero no los abordaremos por ahora, pues ya han sido publicados ${ }^{102}$.

\section{No cualquier interés público legitimo posee la entidad necesaria para} vencer la reserva.

En acceso a la información pública hay un ejemplo ilustrativo de la Corte Suprema de EE. UU. en "Departamento de Defensa v. Federal Labor Authority" (1994). Dos sindicatos de un organismo público solicitaron conocer los domicilios de los funcionarios de tal entidad. Se fundó en que uno de los propósitos de la Ley Laboral es facilitar una efectiva comunicación entre los empleados en procesos de negociación colectiva. Aunque el fallo reconoció i. p. en la solicitud, el acceso fue denegado al estimar que la consecución de dicho interés no traía aparejado la obtención del fin de la Ley de acceso a la información, de promover el derecho a conocer el desempeño de las actividades gubernamentales, por lo que el interés de los requirentes, aunque reconocido y público, era "insignificante" 103 en comparación al interés de los afectados en mantener la reserva de sus domicilios. El acceso requerido, sostuvo la Corte Suprema norteamericana, "no promovería considerablemente el derecho de los ciudadanos a ser informados de lo que el gobierno hace"104.

$\mathrm{Si}$ bien el tribunal reconoce la existencia de un i. p. en el requerimiento, admite asimismo que no debe tratarse de cualquier i. p. sino de uno que contribuya "significativamente a la pública comprensión de las operaciones $o$ actividades del gobierno" 105 . Este es el único i. p. digno que habría justi-

${ }^{101}$ Corte de Apelaciones de Santiago, rol 3.436-2010, que acogió un reclamo de ilegalidad interpuesto por la Dirección Nacional de Servicio Civil contra la decisión del Consejo para la Transparencia, que había ordenado a dicho organismo revelar lo solicitado. Aunque el Consejo sostuvo que el Servicio Civil no había acreditado cómo la publicidad de la información requerida comprometería el interés nacional (c. $2^{\circ}$ ), la Corte acogió la idea que la Ley $\mathrm{N}^{\circ} 19.882$, en cuanto protege "el interés público en la confidencialidad de los procesos de selección" a que se refiere dicho cuerpo legal $\left(\mathrm{c} .17^{\circ}\right)$ cuyo fin se frustraría de seguirse la interpretación postulada por el Consejo $\left(\right.$ c. $\left.21^{\circ}\right)$.

${ }^{102}$ Sanz Salguero, Francisco, Solicitud de acceso a la información y tutela de los datos personales de un tercero, en Revista de Derecho de la Pontificia Universidad Católica de Valparaíso, 41 (2013), p. 492, se refiere la decisión amparo No C1225-12, del 28 de noviembre de 2012 (c. 4).

${ }^{103}$ Corte Suprema de Estados Unidos, "U.S. Dept. of Defense v. Federal Labor Authority", 510 U.S. 487, 9-10: "El interés público relevante en este caso es insignificante".

${ }^{104}$ Ibíd.

${ }^{105}$ Ibíd., 8, donde se cita "Dept. of Justice v. Reporters Committee for Freedom of the Press" 489 U.S. 775. 
ficado llevar a cabo aquello que, según la ley y su historía fidedigna, debe realizarse en estos casos: "un balance de intereses entre la protección de los asuntos privados de una persona y la consecución del derecho del público a la información gubernamental' ${ }^{106}$. Se balancean intereses o bienes en cierto grado equivalentes, pero en este caso, aunque legítimo, no alcanzaba a configurar un interés digno para siquiera entrar a confrontar el derecho a la privacidad.

En Chile, un ejemplo, ya revisado, sobre libertad de expresión y vida privada es el fallo de primer grado de "Doctora Cordero" (2011). A pesar de reconocer que podía haber i. p. en la información, sostuvo que dicho i. p. carecía de la certidumbre y entidad como para justificar la intromisión en la intimidad de la afectada: "aun cuando los encartados aducen un interés público comprometido para llevar a efecto la grabación o difusión, argumentando que la [...] [Ley de Prensa] habría obrado, en su concepto, como causal de justificación, recogida con ese carácter en el inciso final del artículo $161 \mathrm{~A}$ del Código Penal, la propia ley limita el ejercicio de ese derecho, límites que no resguardan sino las otras garantías constitucionales de igual envergadura, como son la intimidad, el honor y la propia imagen, y en presencia de un concepto jurídico indeterminado como es el llamado 'interés público comprometido', sólo el eventual afectado, la ley o la autoridad judicial pueden justificar la conculcación de esos derechos por bienes jurídicos que el ordenamiento cautele con mayor celo, el que en la especie (el correcto uso de los beneficios de la seguridad social) no tiene la entidad de las garantías constitucionales cuya colusión se sopesa en el caso de autos" 107.

Aunque algunos pasajes parecen negar la existencia de un i. p. ${ }^{108}$ o incluso afirmar que con independencia de su existencia lo realmente clave era que la información había sido obtenida subrepticiamente ${ }^{109}$, lo claro es que cuando se reconoce su concurrencia -"el correcto uso de los beneficios de seguridad social'-, el aludido i. p. no era suficiente como para justificar la injerencia en la vida privada de los afectados. Apelado el fallo,

${ }^{106}$ Informe del Senado, cit. por HaLSTUK, M., cit. (n. 86), p. 125, que dijo: " $L a$ oración 'clara e injustificada invasión a la privacidad personal enuncia la aplicación de una medida que supondrá un balance de intereses entre la protección de los asuntos privados de una persona y la consecución del derecho del público a la información gubernamental'.

${ }^{107} 22^{\circ}$ Juzgado del Crimen de Santiago, rol 3.913-2003 ("Jaime Lara y otros con María Luisa Cordero"), c. $11^{\circ}$

${ }^{108}$ Ibíd., c. $13^{\circ}$.

${ }^{109}$ Ibíd., c. $19^{\circ}$. 
fue confirmado en segunda instancia ${ }^{110}$ y revocado por la Corte Suprema, como ya se expuso.

3. El interés público en el asunto no extiende su efecto justificante sobre aspectos que no son de interés público.

A pesar de las objeciones ya expuestas a la doctrina del Tribunal Constitucional español, hay casos en que éste ha resguardado la vida privada no obstante admitir que el tema o asunto sobre el que se vinculaba la información era de i. p. La solución ha ido por el lado de estimar que ciertos aspectos o detalles efectivamente publicados eran innecesarios con miras a la satisfacción del i. p. en juego. Un ejemplo ilustrativo es el caso "Arquitecto con Sida" (1992). Un diario de Baleares publicó que el aludido profesional padecía dicha enfermedad, señalando, además, que él convivía con un compañero (publicando su edad e iniciales). Ambos demandaron judicialmente acción indemnizatoria por intromisión en su derecho a la intimidad y obtenidas éstas, el Tribunal Constitucional hubo de pronunciarse frente a un recurso interpuesto por el periódico ante el mismo tribunal.

Este, luego de reconocer que la persona individualizada padecía "una enfermedad cuyas causas y vías de propagación han generado y generan una alarma social" añadió que "la identificación de las personas así supuestamente afectadas por tal enfermedad fue, en el sentido más propio de las palabras, irrelevante a efectos de la información que se quiso transmitir, pues si ninguna duda hay en orden a la conveniencia de que la comunidad sea informada sobre el origen y evolución, en todos los órdenes, de un determinado mal, no cabe decir lo mismo en cuanto a la individualización directa o indirecta, de quienes lo padecen [...]. Tal información no es ya de interés público, y no lo fue aqui, con la consecuencia, ya clara, de que su difusión comportó un daño o, cuando menos, una perturbación injustificada por carente, en rigor, de todo sentido"111.

Interesante es constatar que el Tribunal Constitucional español estimó que la información revelada no sólo vulneraba la intimidad (esto no sería un argumento fuerte de cara a una información de indudable i. p. ) sino que lo hace de un modo absolutamente innecesario para comunicar aquello que es de i. p. . Algo semejante ha resuelto el referido tribunal en casos posteriores, en que ha afirmado que "el supuesto interés general de la noticia no justifica en el presente caso la publicación de ésta en la forma en que se ha efectuado" 112 .

${ }^{110}$ Corte de Apelaciones de Santiago, rol 1781-2011.

${ }^{111}$ Tribunal Constitucional de España, rol 20/ 1992, FJ 3. Un fallo similar en Tribunal Constitucional de España, rol 172/ 1990.

${ }^{112}$ Tribunal Constitucional de España, rol 127/2003, FJ 8. 


\section{El interés público no puede prevalecer frente a la cobertura más sensible de la vida privada.}

Hay casos en los que se ha estimado que el i. p. debe sustraerse cuando pueden perjudicarse aspectos sensibles de la vida privada. Aunque esta modalidad puede parecer afín a una de las posiciones ya expuestas -los derechos como "triunfos" frente a consideraciones de bienestar- parece situarse más bien en la línea de admitir que si bien los derechos deben ajustarse a las exigencias del bien común, no deben hacerlo al punto de desconocer que hay ciertas exigencias de justicia inconmensurables, identificables en unos pocos derechos absolutos (prohibición de matar directamente a un inocente o de torturar) o en algunos aspectos inviolables de ciertos derechos no absolutos (cobertura más sensible de la intimidad, de la libertad religiosa o de la igualdad).

Algo así es posible constatar, implícitamente, en ciertas decisiones del Consejo para la Transparencia que sin perjuicio de estar en buena medida orientadas bajo las coordenadas del balanceo utilitarista ${ }^{113}$, en ocasiones han admitido que hay coberturas sensibles de la vida privada que no pueden ser superadas por el i. p. Por ejemplo, se ha resuelto que la solicitud de acceso sobre selección de cargo y evaluación personal debe entregarse, salvo los "datos sensibles de la persona seleccionada" 114 . En tal sentido se han pronunciado otras decisiones del Consejo para la Transparencia, que a propósito de los estados de salud, han reconocido implícitamente que los datos sensibles son un núcleo irreductible que no puede someterse a la satisfacción de fines ulteriores como el i. p. ${ }^{115}$ En otros casos se estimó no dar acceso a la identidad personal contenida en ciertos expedientes ya que su comunicación podría haber afectado la estabilidad del empleo de los denunciantes o exponerlos a represalias ${ }^{116}$. Es un modo de reconocer que no obstante tratarse de datos personales-no sensibles su difusión podría tornarlos sensibles por las circunstancias del caso ${ }^{117}$.

${ }^{113}$ Covarrubias Cuevas, Ignacio, Las falencias de test de interés público como instrumento de ponderación entre el acceso a la información pública y la vida privada, en Revista de Derecho Pontificia Universidad Católica de Valparaíso, 38 (2012), pp. 499-541.

${ }^{114}$ Consejo para la Transparencia, Decisión A29-09, c. 10, h); Decisión A11009 , c. $8^{\circ}$, e). Similarmente, Consejo para la Transparencia, Decisión C533-09, c. $3^{\circ}$ y $4^{\circ}$; y Decisión C711-10, c. $11^{\circ}$, citado, también en Covarrubias Cuevas, I., La vida privada de las figuras públicas, cit. (n. 1), p. 214.

${ }^{115}$ Consejo para la Transparencia, Decisión C198-10, c. $8^{\circ}$ ss., citada en CovaRRUBias Cuevas, I., La vida privada de las figuras públicas, cit. (n. 1), pp. 214-215.

${ }^{116}$ Consejo para la Transparencia, Decisión A53-09, c. $11^{\circ}$ a $14^{\circ}$, replicado en Decisión C335-10, c. 6º citadas en Covarrubias Cuevas, I., cit. (n. 1), p. 214.

${ }^{117}$ Covarrubias Cuevas, I., La vida privada de las figuras públicas, cit. (n. 1), p. 214. 


\section{VI. ¿EN QUÉ SENTIDO LOS CRITERIOS OBSERVADOS} PUEDEN CONTRIBUIR A UNA MEJOR INTERPRETACIÓN DEL ARTÍ́CULO 30 DE LA "LEY DE PRENSA"?

Junto con la noción extendida de i. p. - un interés prevalente cuya concurrencia produce el efecto de desplazar la tutela de ciertos derechos- es posible observar que en el resguardo de ciertos derechos, en concreto de la vida privada, también es posible identificar bienes que constituyen aspectos del mismo i. p. a preservar. Del mismo modo como se contribuye al i. p. cuando el ejercicio de la libertad de expresión o el derecho de acceso se refiere a materias que comprometen bienes compartidos por todos-orden, la seguridad, la salud o la moralidad pública, transparencia- también se colabora con el bien común cuando la protección de la vida privada, más allá de lo que implica el resguardo de un bien individual, puede traer consigo la preservación de ciertos bienes públicos -la confianza en la relación médico paciente (caso "Mitterrand") o la confidencialidad en procesos de selección pública (casos ante el Consejo para la Transparencia) - cuya promoción es tan relevante frente a análogos aspectos del i. p. como aquellos asociados a la libertad de informar.

¿En qué sentido los criterios ya observados pueden contribuir a discernir la interpretación del artículo 30 de la "Ley de Prensa" en cuanto esta disposición reconoce un interés público en los "hechos referentes al desempeño de funciones públicas"? Asumiendo que los "hechos" a los que se refiere la regla son de carácter personal-privado y que la información a difundir incide o puede afectar el ejercicio de una función pública, una aproximación como la habitual procuraría abordar la cuestión en clave disyuntiva y de preferencia condicionada: el i. p. legitimaría el desplazo o disminución en la protección de la vida privada del funcionario, con la salvedad (probable) que los datos íntimos fueren tan sensibles que se estimaren parte de una cobertura inviolable de la intimidad.

Un abordaje como el propuesto asumiría que el asunto no debe quedar necesariamente reducido a una tensión que ha de afrontarse bajo la lógica ponderativa de un bien colectivo (supuestamente prioritario) enfrentado a un derecho individual, al que no le quedaría más que ceder frente a la prevalencia de un bien superior. Más allá de que en ocasiones es difícil hablar de actos personales que no atañen lo público en tanto común a todos, es posible vislumbrar que tras el resguardo de un derecho fundamental no sólo se protege a su titular sino que por intermedio del resguardo de su conducta jurídicamente protegida es posible identificar una serie de aspectos del i. p. - tan relevantes como el i. p. en la discusión sobre asuntos públicos- cuya preservación o promoción podrían verse comprometida, 
en distinto grado, de no brindarse efectiva tutela al derecho vulnerado.

Si lo anterior es plausible, la aproximación al artículo 30 es bastante más compleja que optar por una solución antagónicamente configurada al asumirse $a b$ initio que cuando el i. p. va de la mando del ejercicio de la libertad de información o del derecho de acceso, este debe prevalecer por referirse a un "bien jurídico superior, como es la publicidad y transparencia de los órganos del Estado"118 o por estar en juego un "bien social prevalente"119. Esta posición binaria dificulta visualizar que tras el resguardo de la vida privada no sólo hay bienes públicos de relevancia análoga a aquellos que es posible disfrutar a partir del legítimo ejercicio de la libertad de expresión, sino que en ocasiones la protección de la privacidad hace posible el cuidado de los mismos bienes proclamados en nombre del despliegue de la libertad que aparece en contraposición. Así, el resguardo de la vida privada puede llevar consigo la protección de la seguridad nacional, bien similar a los que puede traer aparejado la libertad de expresión o el derecho de acceso, como también la promoción del adecuado ejercicio de la función pública, el mismo fin en cuyo nombre aquellos derechos han sido invocados para constreñir la privacidad. Formularemos algunas ideas que contribuyan a entender porqué el ejercicio de la función pública reviste una relevancia tal que justifica la develación de conductas o hechos protegidos por el derecho a la vida privada del funcionario que desempeña tal función.

\section{EL INTERÉS PÚBLICO EN EL EJERCICIO DE UNA FUNCIÓN PÚBLICA: ALGUNAS APROXIMACIONES A PARTIR DE LA "LEY DE PRENSA"}

Sabemos que para el artículo 30 de la "Ley de Prensa", hay i. p. en conocer los hechos que afectan el desempeño de una función pública, aunque tales circunstancias se encuentren habitualmente resguardadas por la esfera privada del funcionario afectado. También hemos observado que había i. p. en la revelación de la enfermedad grave que padecía y ocultaba un ex Presidente en el ejercicio de su cargo (caso "Mitterrand") así como también el manejo de recursos público para fines particulares (caso "Fontevecchia”). Aunque ilustrativos, los criterios expuestos son insuficientes por sí mismos para brindar una orientación normativa conforme a la que sea posible aproximarse a entender porqué en ciertos casos el ejercicio

${ }^{118}$ Corte de Apelaciones de Valparaíso, rol 1.560-2012, en el mismo sentido que la nota 58 .

${ }^{119}$ Consejo para la Transparencia, Decisión A159-09, c. 19. También: Decisión C707-12, c. $10^{\circ}$; Decisión C198-10 c. 20; Decisión A307-09, c. 15\%; Decisión A110-09, c. $8^{\circ}$ y c.9 $9^{\circ}$; Decisión A29-09, c. $8^{\circ}$, en que se afirma que "la privacidad debe ceder en pos del necesario control social que debe ejercerse". 
de la función pública reviste tal interés que justifica develar información cobijada por la privacidad del funcionario que desempeña tal función.

Previo a abordarlo, nos referiremos en breve a ciertos criterios identificados, a partir de algunas fuentes del derecho, que proveen de aspectos valorativos que pueden orientar a discernir la interrogante planteada. Aunque los principios gozan de un carácter universal, el contexto normativo en que son aplicados y las concretas circunstancias son factores insustituibles para dirimir el i. p. en cada caso.

El punto de arranque se colige del objeto de la libertad de informar, esto es, el derecho de las personas "a ser informadas sobre los hechos de interés general" 120 , que en el caso del artículo 30 adopta el nombre de "hechos de interés público". Sabemos que el ejercicio de una función pública es un hecho de i. p. para la Ley $\mathrm{N}^{\circ} 19.733$, sin embargo, la razón de fondo-aquello que confiere tal cualidad prevalente al ejercicio de dicha función- sigue pendiente. Un segundo abordaje de la historia fidedigna de la Ley de Prensa, donde se desprende la orientación de la referida noción. Hay constancia en las actas legislativas que la expresión i. p. está referida al "bien común”. Se dijo que lo que legitima la difusión de la información es la defensa de "un interés público real de bien común"121. Luego se acordó "que por interés público real debe entenderse el interés de la sociedad y no sólo el del Estado" ${ }^{122}$. En apoyo a dicho aserto, el senador Hernán Vodanovic no fue partidario de añadir a la oración “interés público real” el término “de bien común”, al estimar que éste se entendía incorporado en aquella expresión, por lo que su incorporación resultaba superflua para tales efectos ${ }^{123}$.

Una tercera aproximación es que el i. p. -al que se refieren las fuentes del derecho examinadas- parece ser un concepto normativo que se vincula con la identificación de ciertos bienes que nos interesa preservar como sociedad, por ejemplo, aquello que "incide en la marcha del Estado" o en el cumplimiento de sus funciones insustituibles, como las de dirección política y administrativa, la función jurisdiccional y la provisión de normas jurídicas, entre otras tareas (públicas) que comprometen el ejercicio de la justicia distributiva. Sobre este punto volveremos enseguida por ser

${ }^{120}$ Ley $\mathrm{N}^{\circ} 19.733$, sobre: Libertades de opinión e información y ejercicio del periodismo, publicada el 4 de junio de 2001, artículo 1 inciso $3^{\circ}$.

${ }^{121}$ Comisión de Constitución, Informe $\mathrm{N}^{\circ} 1.549$ sobre proyecto de Ley $\mathrm{N}^{\circ}$ 19.048, sobre Libertad de expresión.

${ }^{122}$ Comisión de Constitución, Informe $N^{\circ} 1.553$ sobre proyecto de Ley 19. 048, sobre Libertad de expresión.

${ }^{123}$ Comisión de Constitución, Informe $\mathrm{N}^{\circ} 1.549$ del proyecto de Ley 19.048, sobre Libertad de expresión. 
uno de los más cruciales para dilucidar no sólo la presencia del i. p. sino también su prevalencia en el caso concreto.

Lo dicho contribuye a advertir -en línea con el derecho comparadoque la función pública cuyo desempeño interesa al i. p. no es únicamente aquella que puede ser comprometida por "funcionarios públicos" en sentido formal, sino también por servidores públicos elegidos, designados o candidatos a dichas labores ${ }^{124}$. Lo relevante es el "funcionario público", en sentido lato, en cuanto contribuye significativamente en la administración y distribución de los bienes y cargas comunes. Esto explica que ciertas labores ejercidas desde el ámbito particular, puedan a veces revestir i. p., lo cual explica la plausibilidad de una de las hipótesis reconocidas por la Ley de Prensa, que atribuye i. p. a los hechos "realizados en el ejercicio de una profesión u oficio y cuyo conocimiento tenga interés público real", aunque no se trate de una funcion ejercida por un funcionario público. La función ejercida por el piloto de una línea aérea comercial-privada es una función de indudable i. p. aunque no sea la función ejercida por un funcionario público.

En quinto lugar, parece evidente que no basta sólo con verificar que la conducta o circunstancia del funcionario en cuestión haya incidido o pueda incidir negativamente en el desempeño de la función pública que ejerce. La aludida afectación debe poseer cierta entidad como para comprometer en algún grado significativo el i. p. No puede tratarse de cualquier incidencia en su cumplimiento. Tampoco de cualquier función pública ni de cualquier funcionario, por muy digna que sea su labor y por muy negligente que haya sido su ejecución, a menos que dicho incumplimiento haya tenido un rol significativo en los daños que de ello se siguieron o en los bienes que dejaron de preservarse.

Estas últimas consideraciones contribuyen a identificar situaciones en las que si bien podría sostenerse formalmente la existencia de un i. p. según el artículo 30 de la "Ley de Prensa", ello no supondría necesariamente su concurrencia según un criterio sustan tivo. Dicho de otro modo: si nos ciñéramos estrictamente al texto, podría justificarse la revelación pública de ciertos aspectos de la vida privada de cualquier funcionario público que se encontrare en el ejercicio de cualquier función cuyo desempeño pudiera verse eventualmente comprometida por su conducta personal o con ocasión de un hecho padecido por dicho funcionario. Esto, además

${ }^{124}$ Warren, Samuel - Brandeis, Louis, The Right to Privacy, en Harvard Law Review, 4 (1890), p. 215, los asuntos de i.p. son los "que conciernen la vida, hábitos, actos [...] privadas de un individuo" y "posean legítima conexión con su aptitud para un cargo público que busca o para el cual esté siendo propuesto, o para cualquier posición pública o cuasi pública que busque o para la cual esté siendo propuesto”. 
de ser injusto con las personas afectadas y carente de fundamento en la perspectiva de la interpretación jurídica, tampoco se condeciría con el propósito de este derecho de informar "hechos de interés general".

\section{VIII. ¿POR QUÉ EL EJERCICIO DE UNA FUNCIÓN PÚBLICA COMPROMETE O PUEDE COMPROMETER SIGNIFICATIVAMENTE EL INTERÉS PÚBLICO?}

En vistas que no necesariamente toda afectación a la función pública atribuible a la acción personal del funcionario reviste i. p. que justifique la divulgación de la información resguardada por la vida privada, daremos algunas ideas para evaluar cuándo nos encontramos, como dice la "Ley de Prensa", frente a un "interés público real', esto es, frente a un hecho o conducta que comprometa o pueda comprometer significativamente " $\mathrm{el}$ interés de la sociedad", el "bien común” o alguna de sus manifestaciones, como consecuencia del perjuicio de la función pública desempeñada. ¿Cuáles son entonces aquellos bienes o intereses cuya perturbación justifica la develación de aquello que ordinariamente está protegido por la reserva de la vida privada? Son variados y múltiples los bienes e intereses que guardan bajo su cuidado quienes desempeñan funciones públicas. No sólo tienen a su cargo la preservación del orden público, la seguridad nacional, la salud y la moralidad pública, sino también la justa distribución de bienes y cargas así como la administración de la riqueza común, entre otras indispensables tareas. Estas son algunas de las manifestaciones del i. p. que parecen concitar un apoyo bastante transversal en cuanto a la necesidad de preservar o promover su disfrute común.

En tal contexto, el ejercicio de la función pública es una tarea que, en distinto grado, persigue contribuir a la justa distribución de los bienes y cargas comunes y a la eficaz administración de los mismos. De ser cierto, por extensión habría i. p. en conocer en qué sentido la conducta personal de un servidor público o alguna circunstancia suya que lo afecte podría incidir significativamente en la promoción u obtención de esta finalidad común por la vía de comprometer el desempeño de su función.

Como ya lo señalamos, estas distintas manifestaciones del i. p. son habitualmente singularizadas y descritas en los ordenamientos constitucionales y convenios internacionales, bajo expresiones tales como "orden público", "seguridad nacional”, "salud pública” y "moralidad pública”, además de otros términos menos comunes como la "imparcialidad en la administración de justicia”, la "probidad" y la "publicidad o transparencia estatal”, entre otros aspectos constitutivos del mismo bien común. Al tratarse de bienes cuya preservación y cuidado interesa a todos, su lesión (o 
la omisión en su conservación) se extiende consecuencial y negativamente sobre todos, en distinto grado. Atendido el carácter común de los referidos bienes es que su resguardo constituye un supuesto insoslayable para que las personas puedan disfrutar de sus derechos ${ }^{125}$.

Por otra parte, si bien muchas manifestaciones del bien común o i. p. pueden satisfacerse simultáneamente y en grado equivalente, hay casos en que el resguardo o promoción de uno de ellos disminuye el goce de otro aspecto del bien común o el ejercicio de un derecho, por lo que debe ponderarse cuál de ellos debe preferirse para promover un bien mayor o impedir un mal. Esto explica que en ocasiones la prosecución de un bien (la transparencia pública o el ejercicio de la libertad informativa sobre un asunto de interés público) pueda afectar la preservación de otros bienes (la seguridad nacional o la reputación de terceros) por lo que surge la necesidad que ponderar cuál de ellos es conveniente privilegiar en un momento determinado.

Por ello estimamos indispensable encauzar la libertad en la medida que su despliegue en nombre de algún derecho no exceda el interés puramente individual y pase a comprometer el goce de ciertos bienes comúnmente compartidos. De aquí arranca la razón que sustenta que buena parte de las cartas políticas y convenciones internacionales de derechos humanos hayan sometido la gran mayoría del ejercicio de los derechos a las exigencias que el bien común impone y, a las limitaciones especificadas en cada derecho. Así, aquello que confiere i. p. al ejercicio de una función pública es el mismo interés público, bien común o alguna de sus manifestaciones, cuando aquél o éstas pueden haber sido seriamente comprometidas con ocasión del ejercicio de una potestad pública o potestad particular pero que tiene interés común (en caso que no fueren funcionarios).

En fin, pareciera ser que las posiciones más extendidas sobre el i. p. y los derechos no gozan de la flexibilidad necesaria para contribuir en discernir lo que efectivamente está en juego cuando los aludidos derechos (y los bienes que éstos representan) aparecen confrontados. Mientras algunos ven al interés público o las distintas manifestaciones del bien común como una amenaza a los derechos, otros conciben a buena parte de éstos como expresiones de intereses individuales o particulares que deben ceder frente a las exigencias colectivas. Confiamos, por el contrario, en la idea de que el i. p. puede operar como límite que encauce el ejercicio de los derechos individuales en pos de la convivencia, pero ya no únicamente como coto

${ }^{125}$ FINNIS, John, Natural law and Natural rights (Oxford, Oxford University Press, 1980) p. 220, dice que estos aspectos del bien común son "un marco necesario para disfrutar [de los derechos] en su conjunto". 
externo a su ejercicio, sino más bien en el entendido que el mismo bien común -y sus manifestaciones- pueden ser un elemento definitorio y modulador del ejercicio de los derechos.

\section{Conclusiones}

$1^{\circ}$ La valoración del i. p. como estándar justificador de injerencias no consentidas en el derecho a la vida privada supone un proceso de discernimiento más complejo de lo que ordinariamente puede observarse a partir de las posiciones más extendidas y contrapuestas sobre la relación entre el i. p. y los derechos fundamentales.

$2^{\circ}$ Mientras unos enfatizan la preeminencia del i. p. para restringir el ejercicio de los derechos (v.gr., la vida privada) y otros acentúan la contención que éstos suponen frente a las consideraciones de bienestar general, ambas nociones comparten la idea de que existe una contraposición entre el resguardo a los derechos y la protección del i. p.

$3^{\circ}$ Hay casos, sin embargo, que exhiben que la relación entre i. p. y vida privada puede ser abordado desde una perspectiva que trascienda el todo o nada de las aproximaciones más encontradas, en que el i. p. y la vida privada no son necesariamente observados como categorías excluyentes entre sí y donde los derechos -incluido, el derecho a la vida privada- pueden ser considerados como parte integrante del mismo i. p. a promover y no necesariamente como un escollo para su satisfacción.

$4^{\circ}$ Tales ejemplos desafían las posiciones contrapuestas sobre el i. p. y los derechos, pues muestran que puede haber una serie de bienes o intereses comunes tanto en el resguardo de la vida privada como en el de la libertad de expresión y el derecho de acceso -habitualmente descritos como aspectos del orden público, salud, moralidad pública, correcta administración de justicia, transparencia, entre otras manifestaciones del bien común- por lo que el discernimiento acerca del i. p. y el derecho a la privacidad no debe traducirse necesariamente en un abordaje excluyente y menos todavía en uno en que el efecto previsible sea el desplazamiento de la privacidad por el sólo hecho de constatar la presencia de un i. p. en la difusión de cierta información.

$5^{\circ}$ La libertad de informar un asunto de relevancia pública y la transparencia son manifestaciones del i. p. que deben ponderarse con otras expresiones del mismo que estén involucrados, por lo que, en dicho discernimiento, el i. p. en la vida privada puede ser considerado más relevante que el i. p. en la información, o bien, puede concluirse que no cualquier i. p., aun legítimo, posee la entidad necesaria para vencer la reserva.

$6^{\circ}$ Así, el i. p. no sólo puede legítimamente restringir el derecho a la 
vida privada, como habitualmente se reconoce, sino también el ejercicio de la libertad de expresión.

$7^{\circ}$ Lo anterior ocurre porque tras el resguardo de la vida privada no sólo hay bienes públicos de relevancia análoga a aquellos que es posible disfrutar a partir del legítimo ejercicio de la libertad de expresión, sino que, a veces, la protección de la privacidad hace posible el cuidado de bienes de similar importancia a aquellos proclamados en nombre del despliegue de la libertad de expresión o del derecho de acceso.

$8^{\circ}$ No basta identificar el i. p. con un bien superior cuya presencia desplaza al derecho concurrente, ni tampoco como uno cuya prevalencia constituye una amenaza para los derechos fundamentales, sino más bien como un aspecto del bien común -ponderable a otros aspectos análogos del mismo- que junto con servir de cauce al ejercicio de los derechos constituya un elemento definitorio y modulador de éstos.

\section{BiBLIOGRAFÍA}

Aleinikoff, Alexander, Constitutional Law in the Age of Balancing, en Yale Law Journal, 96 (1987).

AleXY, Robert, $A$ Theory of Constitutional Rights (New York, Oxford University, 2002).

Alexy, Robert, On Balancing and Subsumption. A Structural Comparison, en Ratio Juris, 16 (2003) 4.

ALEXY, Robert, El concepto y la validez del derecho (Traducción de Jorge M. Seña, 2a edición, Barcelona, Gedisa, 1997).

ALEXY, Robert, Teoría de la argumentación jurídica: La teoría del discurso racional como teoría de la fundamentación jurídica (Traducción de Manuel Atienza e Isabel Espejo, Madrid, Centro de Estudios Constitucionales, 1989).

BAZÁN, Víctor, El derecho a la vida privada y el derecho a la libertad de información en la doctrina y jurisprudencia de la Corte Suprema de Justicia argentina, en Estudios Constitucionales, 6 (2008) 1.

Bernal Pulido, Carlos, El principio de proporcionalidad y los derechos fundamentales (Madrid, Centro de Estudios Políticos y Constitucionales, 2003).

Cea Egaña, José Luis, Derecho constitucional a la intimidad y a la honra, en Revista de Derecho de la Universidad Católica del Norte, 5 (1998).

Cea Egaña, José Luis, Derecho constitucional chileno (Santiago, Universidad Católica de Chile, 2004), II.

CEA Egaña, José Luis, Vida pública, vida privada y derecho a la información: acerca del secreto y su reverso, en Revista de Derecho de la Universidad Austral de Chile, 3 (1992) 1-2.

Corral TAlCIANI, Hernán, Sobre la responsabilidad civil de los periodistas y de los medios de comunicación social por atentados a la honra, intimidad e imagen, en Información Pública, 4 (Escuela de Periodismo Universidad Santo Tomás, 2006) 2 [visible en: http://corraltalciani_files.wordpress.com/2010/04/resp-civil-de-periodistas.pdf, visitadea el 31 de julio de 2014].

Covarrubias Cuevas, Ignacio Evaluación crítica de la noción de que los funcionarios 
públicos tienen una intimidad más reducida que la de una persona ordinaria, en Revista Chilena de Derecho, 41 (2014) 3, publicación pendiente.

COVARRUBias Cuevas, Ignacio, La renuencia del derecho británico a la regla optimizadora en el test de proporcionalidad (y la constatación del mismo resultado en el TC chileno), en Ortiz, David - Aquize, Katty (coordinadores), Tendencias actuales del Estado constitucional contemporáneo (Lima, Ara Editores, 2013) V.

Covarrubias Cuevas, Ignacio, ¿Emplea el Tribunal Constitucional el test de proporcionalidad?, en Estudios Constitucionales, 12 (2014) 1.

Covarrubias Cuevas, Ignacio, La vida privada de las figuras públicas (Santiago, Thomson-Reuters, 2013).

Covarrubias Cuevas, Ignacio, La vida privada de los funcionarios públicos frente a dos derechos: el acceso a la Información Pública y la libertad de expresión. (Criterios empleados por la jurisprudencia chilena y comparada y su importancia relativa), aceptado para su publicación en Ius et Praxis, 21 (2015) 1.

Covarrubias Cuevas, Ignacio, Las falencias de test de interés público como instrumento de ponderación entre el acceso a la información pública y la vida privada, en Revista de Derecho de la Pontificia Universidad Católica de Valparaíso, 38 (2012).

De Otто y Pardo, Ignacio, Derechos fundamentales y Constitución (Madrid, Civitas, 1988).

Díaz Tolosa, Regina, Delitos que Vulneran la intimidad de las personas: Análisis crítico del artículo 161-A del Código Penal chileno, en Ius et Praxis, 13 (2007) 1.

DworkIn, Ronald, Taking Rights Seriously (Cambridge, Harvard University Press, 1977).

Eguiguren Praeli, Francisco, La libertad de expresión e información y el derecho a la intimidad personal. Su desarrollo actual y sus conflictos (Lima, Palestra Editores, 2004).

ETzioni, Amitai, The Limits of Privacy (Nueva York, Basic Book, 1999).

Eva Parada, María José, Fallo "Páez con Barahona": libertad de expresión e interés público, en Anuario de Derechos Humanos, 1 (2005).

Evans DE LA CuAdra, Enrique, Los derechos constitucionales (Santiago, Editorial Jurídica de Chile, 1986).

Fallon, Richard, Individual Rights and the Powers of Government, en Georgia Law Review, 27 (1993).

FINNIS, John, Natural law and Natural rights (Oxford, Oxford University Press, 1980).

FLORES, Oscar, Libertad de prensa y derecho a la intimidad de los funcionarios públicos (Buenos Aires, La Ley, 2004).

Gardbaum, Stephen, Limiting Constitutional Rights, en UCLA Law Review, 54 (2007).

Glendon, Mary Ann, El lenguaje de los derechos, en Estudios Públicos, 70 (1998).

González Cifuentes, Carolina, El derecho a la intimidad de los altos cargos (Tesis doctoral de la Universidad de Salamanca. Visible en: http://gredos.usal.es/jspui/ bitstream/10366/115568/1/DDPG_Gonzalez_Cifuentes_C._El_derecho.pdf_

GRISOLÍA, Francisco, Libertad de expresión y derecho a la honra (Santiago, LexisNexis, 2004).

Habermas, Jürgen, Between Facts and Norms: Contributions to a Discourse Theory of Law and Democracy (Cambridge, MIT U. Press, 1996).

Halstuk, Martin, Blurred Vision: The Supreme Court's FOIA Opinions on Invasion of Privacy, en Davis, Charles - Splichal, Sigman (editores), Access Denied. Freedom of Information in the Information Age (Iowa, Iowa State University Press, 2000). 
Jara Villalobos, Camilo, Derecho a la privacidad, libertad de expresión e interés público: el caso "Cordero con Lara y otros", en Anuario de Derechos Humanos, 10 (2014).

Kumm, Mattias, Constitutional Rights as Principles: On the Structure and Domain of Constitutional Justice, en International Journal of Constitutional Law, 2 (2004).

Lovera Parmo, Domingo, El interés público como estándar. Libertad de expresión y vida privada, en GonzÁLEZ, Felipe (editor): Libertad de expresión en Chile (Santiago, Universidad Diego Portales, 2006).

MacIntyre, Alasdair, Tras la virtud (Madrid, Austral, 2013).

Matus Acuña, Jean Pierre - Hernández Basualto, Héctor, Materiales de discusión presentados a la Comisión Foro Penal, Parte especial. Versión refundida de unidades 1 a 9, con las observaciones recibidas y las conclusiones arribadas en las sesiones del Foro Penal, en Politica Criminal D3 (2006), [visible en: http://www.politicacriminal. cl/n_01/pdf_01/d_3.pdf, visitado el 4 de agosto de 2014].

Meins Olivares, Eduardo, Derecho a la intimidad y a la honra en Chile, en Ius et Praxis, 6 (2000) 1.

Meyerson, Denise, Why Courts Should Not Balance Rights against The Public Interest, en Melbourne University Law Review, 31 (2007).

Nogueira Alcalá, Humberto, El derecho a la libertad de opinión e información y sus Limites (honra y vida privada) (Santiago, LexisNexis, 2002).

Nogueira AlcalÁ, Humberto, Pautas para superar las tensiones entre los derechos a la libertad de opinión e información y los derechos a la honra y la vida privada, en Revista de Derecho de la Universidad Austral de Chile, 17 (2004).

Novoa Monreal, Eduardo, Derecho a la vida privada y libertad de información. Un conflicto de derechos (2a edición, México D.F, Siglo Veintiuno, 1981).

Phillipson, Gavin, The 'right' of privacy in England and Strasbourg compared, en KeNyon, Andrew - Richardson, Megan (editores), New Dimensions in Privacy Law: International and Comparative Perspectives (Cambridge, Cambridge University Press, 2006).

Poole, Diego, Bien común y derechos humanos, en Persona y Derecho, 59 (2008).

Prado, Maximiliano, Limitación de los derechos humanos. Algunas consideraciones teóricas, en Revista Chilena de Derecho, 34 (2007) 1.

Ríos LABbÉ, Sebastián, El derecho a la intimidad en Chile y las últimas modificaciones en su protección civil, en MARTINIC, María Dora (coordinadora), Nuevas tendencias del derecho (Santiago, LexisNexis, 2004).

Sanz Salguero, Francisco, Solicitud de acceso a la información y tutela de los datos personales de un tercero, en Revista de Derecho de la Pontificia Universidad Católica de Valparaiso, 41 (2013).

Schauer, Frederick, A Comment on the Structure of Rights, en Georgia Law Review, 27 (1993).

SCHAUER, Frederick, Commensurability and Its Constitutional Consequences, en Hastings Law Journal, 45 (1994).

Serna Bermúdez, Pedro - Toller, Fernando, La interpretación constitucional de los derechos fundamentales. Una alternativa a los conflictos de derecho (Buenos Aires, La Ley, 2000).

Turle, Marcus, Freedom of Information and Data Protection Law. A Conflict or Reconciliation? en Computer Law \& Security Report, 23 (2007) 6.

Verdugo, Mario - Pffefer, Emilio - Nogueira, Humberto, Derecho constitucional (2a edición, Santiago, Editorial Jurídica de Chile, 1999). 
Vivanco Martínez, Ángela, Curso de derecho constitucional. Aspectos dogmáticos de la carta fundamental de 1980 (Santiago, Ediciones Universidad Católica de Chile, 2006).

Warren, Samuel - Brandeis, Louis, The Right to Privacy, en Harvard Law Review, 4 (1890). 